\title{
Free Rather Than Total Iron Content Is Critically Linked to the Fur Physiology in Shewanella oneidensis
}

\author{
Lulu Liu, Xue Feng, Wei Wang, Yining Chen, Zhe Chen and Haichun Gao* \\ Institute of Microbiology, College of Life Sciences, Zhejiang University, Hangzhou, China
}

\section{OPEN ACCESS}

Edited by:

Patrick Eichenberger

New York University, United States

Reviewed by:

Sun-Shin Cha,

Ewha Womans University,

South Korea

John Senko,

University of Akron, United States

*Correspondence: Haichun Gao

haichung@zju.edu.cn

Specialty section:

This article was submitted to Microbial Physiology and Metabolism, a section of the journal

Frontiers in Microbiology

Received: 10 August 2020 Accepted: 29 September 2020

Published: 26 November 2020

Citation:

Liu L, Feng X, Wang W, Chen Y, Chen $Z$ and Gao H (2020) Free Rather Than Total Iron Content Is Critically Linked to the Fur Physiology in Shewanella oneidensis.

Front. Microbiol. 11:593246. doi: 10.3389/fmicb.2020.593246
Ferric uptake regulator (Fur) is a transcriptional regulator playing a central role in iron homeostasis of many bacteria, and Fur inactivation commonly results in pleiotropic phenotypes. In Shewanella oneidensis, a representative of dissimilatory metal-reducing $\gamma$-proteobacteria capable of respiring a variety of chemicals as electron acceptors (EAs), Fur loss substantially impairs respiration. However, to date the mechanism underlying the physiological phenomenon remains obscure. This investigation reveals that Fur loss compromises activity of iron proteins requiring biosynthetic processes for their iron cofactors, heme in particular. We then show that $S$. oneidensis Fur is critical for maintaining heme homeostasis by affecting both its biosynthesis and decomposition of the molecule. Intriguingly, the abundance of iron-containing proteins controlled by $\mathrm{H}_{2} \mathrm{O}_{2}$-responding regulator OxyR increases in the fur mutant because the Fur loss activates OxyR. By comparing suppression of membrane-impermeable, membranepermeable, and intracellular-only iron chelators on heme deficiency and elevated $\mathrm{H}_{2} \mathrm{O}_{2}$ resistance, our data suggest that the elevation of the free iron content by the Fur loss is likely to be the predominant factor for the Fur physiology. Overall, these results provide circumstantial evidence that Fur inactivation disturbs bacterial iron homeostasis by altering transcription of its regulon members, through which many physiological processes, such as respiration and oxidative stress response, are transformed.

Keywords: iron homeostasis, Shewanella, Fur regulation, heme, oxidative stress

\section{INTRODUCTION}

Iron is a critical nutrient for virtually all living organisms to survive and grow as it is the most common redox active metal found in proteins (Andrews et al., 2003). Naturally, facultatively anaerobic Gram-negative bacteria, such as Escherichia coli, possess hundreds of iron-containing proteins, which participate in an array of biological processes as electron carriers, enzymes, and sensors of environmental and intracellular cues to regulate gene expression (O'Brian, 2015). To facilitate realization of these functions, iron is typically present within heme and iron-sulfur (Fe-S) groups, although there are proteins with iron as mono- and bi-nuclear iron centers (Liu et al., 2014; Rokob et al., 2016). Because of high demand and low solubility of iron in aerobic environments, iron acquisition has always been a challenge to cells, causing iron deficiency to be one of the most common nutritional stresses (Frawley and Fang, 2014). Meanwhile, when overloaded, iron could be highly toxic to cells by efficiently catalyzing biomolecular damages to DNA, proteins, and lipids 
via Fenton reaction (Imlay, 2013). Given that both iron deficiency and overload can be deleterious, it is imperative that cells maintain proper iron homeostasis (Andrews et al., 2003).

In many bacteria, cellular iron homeostasis is primarily regulated by ferric uptake regulator (Fur), which mediates transcription of a cohort of genes in response to iron availability (Fillat, 2014; Seo et al., 2014). Fur mostly works in the classical model of transcriptional repression, based on the extensively studied E. coli paradigm, using ferrous iron $\left(\mathrm{Fe}^{2+}\right)$ as corepressor (Andrews et al., 2003; Sheikh and Taylor, 2009). When iron is plentiful, Fur interacts with $\mathrm{Fe}^{2+}$ to form Fur-Fe $\mathrm{Fe}^{2+}$ complexes, which bind to cis-acting regulatory sequences known as iron-responsive elements (Fur boxes) to block transcription of operons that follow. Under iron depletion conditions, Fur becomes inactive because of the lack of the metal co-repressor, and derepression occurs (Andrews et al., 2003).

It is well established that repression of iron acquisition genes is the main and highly conserved physiological function of Fur (Fillat, 2014; Seo et al., 2014). Derepression of the Fur regulon by iron depletion (starvation) should result in increased iron uptake, facilitating normal iron homeostasis to be maintained. By logic, Fur inactivation would allow unchecked iron uptake, which eventually leads to iron overload. In some bacteria, this indeed is the case (Sheikh and Taylor, 2009; Jittawuttipoka et al., 2010; Vajrala et al., 2011; Becerra et al., 2014). However, iron deficiency resulting from fur mutations has also been reported (Keyer and Imlay, 1996; Kitphati et al., 2007; Qi et al., 2012). Moreover, when Fur is inactivated, some bacteria, such as E. coli, suffer from a decrease in the total iron content while facing an increase in the free (unbound) iron content simultaneously (Keyer and Imlay, 1996; Abdul-Tehrani et al., 1999). This has been attributed, at least in part, to constitutive and repressive expression of iron transport and iron storage proteins, respectively. As a consequence, iron uptake and consumption (mainly iron storage) are improperly balanced such that free iron becomes excessive (Andrews et al., 2003).

Shewanella, a group of facultative dissimilatory metalreducing $\gamma$-proteobacteria, have attracted interest for their ability to reduce a wide array of electron acceptors (EAs), and they now serve as a genetic model for studying microbial electrosynthesis (Fredrickson et al., 2008; Rabaey and Rozendal, 2010; Lemaire et al., 2020). The respiratory versatility is attributable to a large repertoire of iron-containing proteins, including hundreds having heme, Fe-S clusters as cofactors, and a dozen or so using iron atom directly to execute catalysis (Imlay, 2014). Among them, heme-containing cytochromes $c$ (cyts $c$ ), in which heme $b$ molecules are covalently attached to polypeptides (Kranz et al., 2009), play a central role in respiration and are unusually abundant: at least 40 cyts $c$ are predicted to be encoded in the genome (Meyer et al., 2004; Gao et al., 2010; Fu et al., 2015). Apparently, the unusually high abundance of iron-containing proteins is a signature of iron-reducing microorganisms because Geobacter species, another group of bacteria renowned for exceptional metal-reducing capacity, contain even a larger number of cyts $c$ (Methé et al., 2003; Lovley et al., 2011). In line with this, Shewanella, as observed in the genus representative S. oneidensis, and Geobacter have iron content that is significantly higher than model bacteria, such as E. coli (Senko and Stolz, 2001; Daly et al., 2004). Because of this, it is conceivable that iron homeostasis plays a particularly important role in endowing metal-reducing bacteria their attractive characteristics.

The importance of iron homeostasis in respiration of both soluble and insoluble EAs in Shewanella and Geobacter has been known for about two decades, and in the former Fur has been identified and suggested to play an critical role in regulation of these processes (Senko and Stolz, 2001; Thompson et al., 2002; Supplementary Figure S1). Subsequent investigations soon established the relationship between iron homeostasis and Fur activity (Wan et al., 2004; O’Neil et al., 2008; Yang et al., 2008). In Shewanella, the loss of Fur results in impaired reduction of a variety of EAs, supporting the proposal that Fur plays a general and critical role in respiration (Yang et al., 2008, 2013; Fu et al., 2018). Although Yang et al. (2013) showed that some of reductase genes are under the direct control of Fur, this level of regulation is unlikely to be a determining factor because the forced production of these genes does not suppress the respective defects observed in the fur mutants (Fu et al., 2018). Instead, the respiratory defects of the fur mutants are largely due to the compromised overall cyt $c$ biosynthesis, presumably a result of reduced heme biosynthesis (Yang et al., 2013; Fu et al., 2018). Given that the Fur loss distorts normal iron homeostasis by reducing total iron while increasing free iron content (Fu et al., 2018), it is reasonable to hypothesize that impaired cyt $c$ biosynthesis (reduced heme content) is a consequence of the imbalanced iron homeostasis.

Here in S. oneidensis, we set out to investigate the influence of Fur loss on various iron-containing proteins, to unravel the mechanism for the reduced heme levels, and to solve inconsistencies observed before. Our data demonstrate that the core of the Fur physiological roles is to prevent the overload of free iron, which is a result of altered transcription of many Fur regulon members upon Fur inactivation. Once free iron levels reach over a threshold, a variety of biological processes are affected and pleiotropic effects of Fur inactivation emerge.

\section{MATERIALS AND METHODS}

\section{Bacterial Strains, Plasmids, and Culture Conditions}

The bacterial strains and plasmids used in this study were listed in Table 1. Sequences of the primers used in this study were available on request. All chemicals were obtained from SigmaAldrich Co., unless otherwise noted. E. coli and S. oneidensis were grown aerobically in LB (Difco, Detroit, MI, United States) at 37 and $30^{\circ} \mathrm{C}$ for genetic manipulation. When appropriate, the growth medium was supplemented with the following: 2 , 6-diaminopimelic acid (DAP), $0.3 \mathrm{mM}$; ampicillin, $50 \mu \mathrm{g} / \mathrm{ml}$; kanamycin, $50 \mu \mathrm{g} / \mathrm{ml}$; gentamicin, $15 \mu \mathrm{g} / \mathrm{ml}$.

For physiological characterization, both $\mathrm{LB}$ and defined medium MS (containing $\mathrm{Fe}(\mathrm{III})\left[\mathrm{FeCI}_{3}\right]$ at $3.6 \mu \mathrm{M}$ ) supplemented with $30 \mathrm{mM}$ L-lactate as electron donor were used (Shi et al., 2015). For aerobic growth, overnight cultures of S. oneidensis strains were inoculated into fresh medium by $200 \mathrm{X}$ 
TABLE 1 | Strains and plasmids used in this study.

\begin{tabular}{|c|c|c|}
\hline Strain or plasmid & Description & Source/references \\
\hline \multicolumn{3}{|l|}{ E. coli strain } \\
\hline $\mathrm{DH} 5 \alpha$ & Host strain for routine cloning & Lab stock \\
\hline WM3064 & $\begin{array}{l}\text { Donor strain for conjugation; } \\
\Delta d a p A\end{array}$ & W. Metcalf, UIUC ${ }^{a}$ \\
\hline \multicolumn{3}{|l|}{ S. oneidensis strain } \\
\hline MR-1 & Wild type & ATCC 700550 \\
\hline HG0266 & $\Delta c c m F$ derived from MR-1 & Jin et al., 2013 \\
\hline HG1070 & $\Delta$ katB derived from $\mathrm{MR}-1$ & Jiang et al., 2014 \\
\hline HG1328 & $\Delta o x y R$ derived from MR-1 & Jiang et al., 2014 \\
\hline HG1783-4 & $\Delta$ feo derived from $M R-1$ & Liu et al., 2018 \\
\hline HG1937 & $\Delta$ fur derived from MR-1 & Gao et al., 2015 \\
\hline HG3030 & $\Delta p u t A$ derived from MR-1 & Dong et al., 2017 \\
\hline HGPUB & $\triangle p u b A B C$ derived from $M R-1$ & Dong et al., 2017 \\
\hline$\Delta$ putA $\Delta$ feo & $\Delta p u t A \Delta f e o$ derived from MR-1 & Liu et al., 2014 \\
\hline HG1111-2 & $\begin{array}{l}\Delta b f r(\Delta b f r 2 \Delta b f r 1) \text { derived from } \\
M R-1\end{array}$ & Fu et al., 2018 \\
\hline HGCYD & $\Delta$ cyd derived from MR-1 & Chen et al., 2015 \\
\hline$\Delta o x y R \Delta f u r$ & $\Delta o x y R \Delta$ fur derived from MR-1 & This study \\
\hline HG3669-7 & $\Delta h m u A X Z$ derived from MR-1 & This study \\
\hline$\Delta h m u \Delta f u r$ & $\Delta$ fur $\triangle h m u A X Z$ derived from $M R-1$ & This study \\
\hline$\Delta f u r \Delta f e o$ & $\Delta$ fur $\Delta$ feo derived from MR-1 & This study \\
\hline$\Delta f u r \Delta p u b$ & $\Delta$ fur $\triangle p u b A B C$ derived from MR-1 & This study \\
\hline$\Delta f u r \Delta b f r$ & $\Delta$ fur $\Delta b$ fr derived from $M R-1$ & This study \\
\hline$\Delta c c m F \Delta f u r$ & $\Delta c c m F \Delta$ fur derived from MR-1 & This study \\
\hline$\Delta c c m F \Delta f u r \Delta h m u$ & $\begin{array}{l}\Delta c c m F \Delta \text { fur } \triangle h m u A X Z \text { derived } \\
\text { from } M R-1\end{array}$ & This study \\
\hline$\Delta p u t A \Delta f e o \Delta h m u$ & $\begin{array}{l}\Delta p u t A \Delta f e o \Delta h m u \text { derived from } \\
\text { MR-1 }\end{array}$ & This study \\
\hline \multicolumn{3}{|l|}{ Plasmid } \\
\hline pHGM01 & $\mathrm{Ap}^{r} \mathrm{Gm}^{r} \mathrm{Cm}^{r}$ suicide vector & Jin et al., 2013 \\
\hline pHGEN-Ptac & $\begin{array}{l}\text { IPTG-inducible Ptac expression } \\
\text { vector }\end{array}$ & Meng et al., 2018a \\
\hline pHGE-Ptac-fur & $\begin{array}{l}\text { Vector for inducible expression of } \\
\text { fur }\end{array}$ & Fu et al., 2018 \\
\hline pHGE-Ptac-bfr & $\begin{array}{l}\text { Vector for inducible expression of } \\
\text { bfr }\end{array}$ & Fu et al., 2018 \\
\hline pHGE-Ptac-oxyR & $\begin{array}{l}\text { Vector for inducible expression of } \\
\text { oxyR }\end{array}$ & Wan et al., 2018 \\
\hline pHGEN-Ptac-hemA & $\begin{array}{l}\text { Vector for inducible expression of } \\
\text { hemA }\end{array}$ & This study \\
\hline pHGEN-Ptac-hmu & $\begin{array}{l}\text { Vector for inducible expression of } \\
\text { hmuAXZ }\end{array}$ & This study \\
\hline pHGEN-Ptac-dpa & $\begin{array}{l}\text { Vector for inducible expression of } \\
\text { B. subtilis } d p a A B\end{array}$ & This study \\
\hline pHGEN-Ptac-dpa & $\begin{array}{l}\text { Vector for inducible expression of } \\
\text { B. subtilis } d p a A B\end{array}$ & This study \\
\hline
\end{tabular}

a UIUC, University of Illinois at Urbana-Champaign.

dilution, shaken at $250 \mathrm{rpm}$ at $30^{\circ} \mathrm{C}$, and growth was recorded by measuring optical density at $600 \mathrm{~nm}\left(\mathrm{OD}_{600}\right)$.

\section{In-Frame Mutant Construction and Complementation}

In-frame deletion strains were constructed using the att-based fusion PCR method as described previously (Jin et al., 2013).
In brief, two fragments flanking the target gene were amplified by PCR with primers containing $a t t B$ and the gene specific sequence, and then linked by a second round of PCR. The fused fragments were introduced into plasmid pHGM01 using the Gateway BP clonase II enzyme mix (Invitrogen) according to the manufacturer's instruction. The resulting vectors were maintained in E. coli DAP auxotroph WM3064 and subsequently transferred into relevant $S$. oneidensis strains via conjugation. Integration of the deletion construct into the chromosome was selected by resistance to Gm and confirmed by PCR. Verified transconjugants were grown in $\mathrm{NaCl}$-less $\mathrm{LB}$ and plated on LB supplemented with $10 \%$ sucrose. Gm-sensitive and sucroseresistant colonies were screened by PCR for intended deletions. Mutants were verified by sequencing the mutated region.

\section{Quantitative Proteomic Analysis by LC-MS/MS}

For sample preparation, $100 \mathrm{ml}$ of MS medium was inoculated with fresh overnight culture by $200 \mathrm{X}$ dilution and incubated at $30^{\circ} \mathrm{C}$ in a shaker $(200 \mathrm{rpm})$ until entering the stationary phase $\left(\sim 0.8\right.$ of $\left.\mathrm{OD}_{600}\right)$. Cultures containing roughly the same number of cells $\left(\sim 10^{10}\right.$ cells) were centrifuged at $8000 \mathrm{rpm}$ for $3 \mathrm{~min}$ at room temperature and pellets immediately frozen in liquid nitrogen and stored at $-80^{\circ} \mathrm{C}$. Three independent biological replicates were used for proteomic analysis following procedures: (i) protein extraction; (ii) trypsin digestion; (iii) TMT/iTRAQ labeling; (iv) HPLC fractionation; (v) LC-MS/MS analysis; (vi) database search; and (vii) bioinformatics methods by PTM-Biolabs (Hangzhou, China) using iTRAQ (Isobaric Tag for Relative Absolute Quantitation) and TMT (Tandem Mass Tags) technology. Tandem mass spectra were searched against the NCBI database. False discovery rate (FDR) thresholds for protein, peptide, and modification site were specified at $1 \%$. Minimum peptide length was set at 7 . For quantification method, TMT6-plex was selected. Data were further analyzed as described previously (Yuan et al., 2012). $P$-values were calculated by MannWhitney test. $P$-values of less than 0.05 were considered as significant. The fold-change cutoff was set when proteins with quantitative ratio change above 1.5 or below $1 / 1.5$. Fold-changes higher than the cutoff were deemed significant.

\section{Controlled Gene Expression}

Controlled gene expression was used in genetic complementation of mutants and assessment of physiological effects of proteins at varying levels. Genes of interest were generated by PCR, cloned into plasmid pHGEN-Ptac under the control of Isopropyl $\beta$-D-1-thiogalactoside (IPTG)-inducible promoter Ptac, and the resultant vectors were transformed into E. coli WM3064 (Meng et al., 2018a). After verification by sequencing, the vectors were transferred into the relevant $S$. oneidensis strains via conjugation. Expression of the cloned genes was controlled by IPTG (Abcam, Shanghai) at varying concentrations.

\section{Droplet Assays}

Droplet assays were employed to evaluate growth inhibition and viability on plates (Jiang et al., 2014). Cells of the exponential 
phase $\left(\sim 0.4\right.$ of $\mathrm{OD}_{600}$, the same throughout the study unless otherwise noted) were collected by centrifugation and adjusted to $10^{8} \mathrm{cfu} / \mathrm{ml}$ (colony forming unit), which was set as the undiluted (dilution factor 0 ). Ten-fold series dilutions were prepared with fresh medium. Five microliters of each dilution was dropped onto LB or MS plates containing required agents. The plates were incubated for $24 \mathrm{~h}$ or longer before being read. All experiments were conducted at least three times.

\section{Disk Diffusion Assays}

Disk diffusion assays were done similarly to those done previously (Jiang et al., 2014). One hundred microliters of exponential phase cultures was spread onto an agar plate containing required chemicals. Paper disks (diameter, $8 \mathrm{~mm}$ ) loaded with chemicals under test were placed on top of the agar. The plates were incubated at $30^{\circ} \mathrm{C}$ for $24 \mathrm{~h}$ prior to analysis.

\section{Chemical Assays}

Through this study, protein concentration was determined with a bicinchoninic acid assay kit with bovine serum albumin (BSA) as a standard according to the manufacturer's instructions (Pierce Chemical). Where needed, standard curves were made with commercial agents each time.

\section{Total Iron}

Total iron contents were determined with the established method (Riemer et al., 2004). Cells entering the stationary phase were collected, washed with phosphate buffered saline (PBS), and adjusted to similar densities $\left(\sim 0.6\right.$ of $\left.\mathrm{OD}_{600}\right)$. Aliquots of $50 \mathrm{ml}$ were mixed with $5 \mathrm{ml}$ of $50 \mathrm{mM} \mathrm{NaOH}$ and sonicated on ice, and centrifuged at $5000 \mathrm{rpm}$ for $10 \mathrm{~min}$. The cell lysates $(100 \mu \mathrm{l})$ were then mixed with $100 \mu \mathrm{l} 10 \mathrm{mM} \mathrm{HCl}$ and $100 \mu \mathrm{l}$ iron releasing reagent (a freshly mixed solution of equal volumes of $1.4 \mathrm{M}$ $\mathrm{HCl}$ and $\left.4.5 \%[\mathrm{w} / \mathrm{v}] \mathrm{KMnO}_{4}\right)$ and treated at $60^{\circ} \mathrm{C}$ for $2 \mathrm{~h}$. After cooling, the iron detection reagents $(6.5 \mathrm{mM}$ ferrozine, $6.5 \mathrm{mM}$ neocuproine, $2.5 \mathrm{M}$ ammonium acetate, and $1 \mathrm{M}$ ascorbic acid in water) were added. The absorbance of samples was measured at $550 \mathrm{~nm} 30 \mathrm{~min}$ later. The standard curve was developed using $\mathrm{FeCI}_{3}$ up to $300 \mu \mathrm{M}$.

\section{Free Iron}

Quantification of free iron was carried out by electron paramagnetic resonance (EPR) spectroscopy (Keyer and Imlay, 1996). Cultures entering the stationary phase $(500 \mathrm{ml})$ were collected by centrifugation and the cell pellets were resuspended in $0.7 \%$ of the original volume of the same medium containing $20 \mathrm{mM}$ desferrioxamine. The sample was incubated at $37^{\circ} \mathrm{C}$ with shaking for $10 \mathrm{~min}$, centrifuged, washed with cold $20 \mathrm{mM}$ Tris- $\mathrm{HCl}, \mathrm{pH} 7.4$, and resuspended in $200 \mu \mathrm{l}$ of the same buffer containing $10 \%$ glycerol. The suspension was scanned with a Bruker EMX plus 9.5/12 spectrophotometer with settings described before (Keyer and Imlay, 1996). Concentrations of intracellular free iron were also assessed by measuring streptonigrin susceptibility with disk diffusion assays.

\section{Heme $b$ and $c$}

Cells entering the stationary phase $\left(\sim 0.8\right.$ of $\left.\mathrm{OD}_{600}\right)$ were harvested and then were lysed with lysis buffer $(0.25 \mathrm{M}$ Tris/ $\mathrm{HCl}$,
[pH 7.5], 0.5\% Triton-X100). The amount of heme $b$ or $c$ was measured following the procedure described elsewhere (Berry and Trumpower, 1987).

\section{Enzyme Assays}

Cultures entering the stationary phase were collected by centrifugation, washed twice with PBS, resuspended in $1 \mathrm{ml}$ PBS, and disrupted by sonication. Cell debris and unlysed bacteria were removed via centrifugation. When necessary, enzymes assays were conducted in anaerobic buffers within the anaerobic chamber.

(i) Catalase was assayed by measuring $\mathrm{H}_{2} \mathrm{O}_{2}$ consumption. $\mathrm{H}_{2} \mathrm{O}_{2}$ were added to reactions containing $100 \mathrm{mg}$ total protein immediately after extract preparation to a final concentration of $1 \mathrm{mM}$, and the reaction mixtures were incubated at $30^{\circ} \mathrm{C}$. Aliquots were taken and assayed for remaining oxidant in a timecourse manner after the treatment began using the ferrous ion oxidation-xylenol orange (FOX) method (Wolff, 1994).

(ii) Cyt bd oxidase. Activity of cyt bd oxidase was assessed by monitoring nitrite tolerance of relevant strains with droplet assay (Fu et al., 2013).

(iii) All metabolic enzymes were assayed in reactions containing $100 \mathrm{mg}$ total protein immediately after extract preparation. Aconitase $(\mathrm{AcnB})$ was assayed with $30 \mathrm{mM}$ citrate in $50 \mathrm{mM}$ Tris- $\mathrm{HCl}, \mathrm{pH} 7.4$ by monitoring the production of cis-aconitate (240 nm) (Varghese et al., 2003). Dihydroxyacid dehydratase (IlvD) was assayed with $390 \mu$ l pre-incubated solutions containing $50 \mathrm{mM}$ Tris ( $\mathrm{pH} 8.0$ ), $10 \mathrm{mM} \mathrm{MgCl}_{2}$, and $10 \mathrm{mM}$ D,L-2,3-dihydroxy-isovalerate by monitoring the production of keto acids (240 nm) (Flint et al., 1993). Peptide deformylase (Def) was assayed with $500 \mu \mathrm{l}$ of $50 \mathrm{mM}$ HEPES buffer ( $\mathrm{pH} 7.5$ ) containing $25 \mathrm{mM} \mathrm{NaCl}, 10 \mathrm{mM} \mathrm{NAD}^{+}, 1$ unit of formate dehydrogenase, and $1 \mathrm{mM}$ formyl-Met-AlaSer (Lazennec and Meinnel, 1997). Threonine dehydrogenase (Tdh) was assayed with $500 \mu \mathrm{l}$ of $50 \mathrm{mM}$ Tris-HCl buffer $(\mathrm{pH}$ 8.4), $1 \mathrm{mM} \mathrm{NAD}^{+}$, and $30 \mathrm{mM}$ threonine (Boylan and Dekker, 1981). Ribulose 5-phosphate 3-epimerase (Rpe) was assayed by with a $500 \mu \mathrm{L}$ reaction mixture containing $50 \mathrm{mM}$ glycylglycine buffer, $\mathrm{pH} 8.5,5 \mathrm{mM}$ diethylene triamine pentaacetic acid, 1 unit of $\alpha$-glycerophosphate dehydrogenase and 10 units of triosephosphate isomerase, $1 \mathrm{mM}$ ribose 5- phosphate, and $0.2 \mathrm{mM}$ NADH (Kiely et al., 1973). Absorbance for Def, $\mathrm{Tdh}$, and Rpe activities were measured at $340 \mathrm{~nm}$. Fumarase (FumB) activity was determined from the appearance of fumarate $(250 \mathrm{~nm})$ with a reaction mixture containing $50 \mathrm{mM}$ sodium phosphate (pH 7.4) and $50 \mathrm{mM}$ malate (Massey, 1955).

\section{Analysis of Gene Expression}

For qRT-PCR, cells of the exponential phase were harvested by centrifugation and total RNA was isolated using RNeasy Mini Kit (Qiagen) according to the manufacturer's instructions. The analysis was carried out with an ABI7300 96-well qRT-PCR system (Applied Biosystems) as described previously (Jiang et al., 2014). The expression of each gene was determined from three replicas in a single real-time qRT-PCR experiment. The Cycle threshold $\left(C_{T}\right)$ values for each gene of interest were averaged and normalized against the $C_{T}$ value of the 16s rRNA gene, whose 
abundance is relatively constant during the log phase. Relative abundance (RA) of each gene was presented (Jiang et al., 2014).

\section{SDS-PAGE and Western Blotting Assays}

Western blotting analysis was performed for detection of $\mathrm{His}_{6}$-tagged proteins as previously described (Dong et al., 2012). Cells entering the stationary phase were harvested by centrifugation, washed with $\mathrm{PBS}(\mathrm{pH}$ 7.0), resuspended in the same buffer, and sonicated. The cell lysates containing the same amount of proteins were subjected to sodium dodecyl sulfate-polyacrylamide gel electrophoresis (SDSPAGE, 10\%). Proteins were then electrophoretically transferred to polyvinylidene difluoride membranes according to the manufacturer's instructions (Bio-Rad). The gels were blotted for $2 \mathrm{~h}$ at $60 \mathrm{~V}$ using a Criterion blotter (Bio-Rad). The blotting membrane was probed with a rabbit polyclonal antibody against $\mathrm{His}_{6}$-tag. Goat anti-rabbit IgG-HRP (horseradish peroxidase) (Roche Diagnostics) was used as the secondary antibody $(1: 5,000)$ and the signal was detected using a chemiluminescence Western blotting kit (Roche Diagnostics). Images were visualized with a UVP imaging system.

\section{Other Analyses}

Student's $t$-test was performed for pairwise comparisons. Values were presented as means \pm standard error of the mean (SEM).

\section{RESULTS}

\section{Proteomic Profiling of the S. oneidensis $\Delta$ fur Strain}

A model illustrating S. oneidensis iron homeostasis containing important components was given to facilitate understanding of the relevant biological processes as a whole and to serve as a general guideline for this study (Figure 1). Investigation presented here was initiated by delineating the proteomic differences inflicted by a fur deletion. The $\Delta f u r$ and its isogenic parental wild-type strains grown aerobically in defined medium MS to $\sim 0.8$ of $\mathrm{OD}_{600}$ (entering the stationary phase) were sampled for proteomics analysis. In total, more than 329 proteins passed the significance threshold (1.5-fold change, $p<0.05$ of a one-way ANOVA and Tukey's HSD post hoc test). Since the $\Delta$ fur strain is impaired in growth, abundance of many proteins having roles in general physiology is likely being indirectly affected. To stay focused, only proteins that are predicted Fur regulon members, involved in iron homeostasis, and directly associated with iron cofactor biosynthesis were discussed here (Figure 2 and Supplementary Tables S1, S2).

We first examined differences in the abundance of top-rated (top 30) Fur regulon members, based on the RSAT (MedinaRivera et al., 2015) weight score of Fur-binding motifs located in promoter regions, between the two strains (Fu et al., 2018). In the $\Delta$ fur strain, $18(60 \%)$ of them were found to be present in significantly increased quantities whereas only $2(6.67 \%)$ showed decreased abundance (Figure 2 and Supplementary Table S1). This result was in perfect agreement with the proposal that Fur

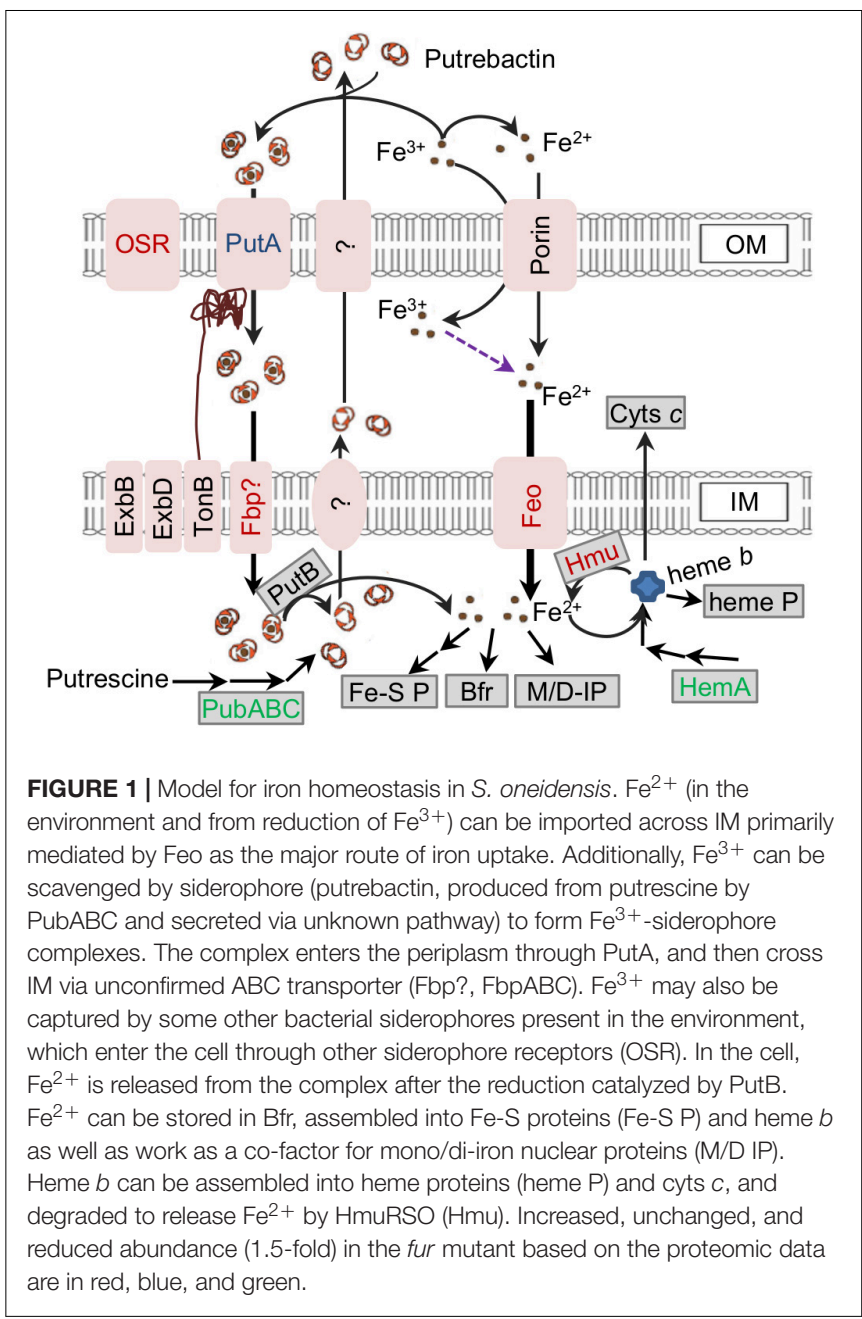

predominantly functions as a transcriptional repressor (Andrews et al., 2003). Clearly, the Fur loss impacted its regulon members that are involved in iron homeostasis most significantly. A large majority of TonB-dependent siderophore receptors (TDSRs) were produced in substantially increased amounts, consistent with the findings that they are induced under iron starvation conditions as well as in the fur mutant (Andrews et al., 2003; $\mathrm{Fu}$ et al., 2018). These receptors have been proposed to have roles in iron uptake via various siderophores produced by other bacteria in the environment (Liu et al., 2018). In line with this, proteins associated with siderophore-iron uptake, such as $\mathrm{FbpABC}$, were also increasingly produced in the fur mutant. On the contrary, Fur-independent TDSR (PutA) for endogenous siderophores, putrebactin, remained rather unaffected by the Fur loss, strongly supporting that the observed differences in protein abundance are largely due to direct regulation of Fur at the transcription level. Expectedly, the Fur loss reduced the quantity of the major iron storage protein Bfr, part of the proposed mechanism that accounts for the iron starvation in the fur mutant (Fu et al., 2018).

In the absence of Fur, iron homeostasis is imbalanced: the total iron content decreases but free iron level increases 
(Fu et al., 2018). This scenario suggests that proteins with iron as a cofactor are likely affected although many of them may not be under the direct control of Fur because of the lack of a Fur-binding motif in their promoter regions. Approximately half of all cyts $c$ (19 out of 40) were detected in the proteome (Supplementary Table S1), which is not surprising because numbers of cyts $c$ identified in previous proteomics studies are similar or even lower crossing a variety of cultivation conditions (Nissen et al., 2012; Yuan et al., 2012). Among cyts $c$ identified, 1 (CcpA), 3, and 15 were up-regulated, unaffected, and down-regulated by the Fur loss, respectively (Figure 2), supporting that Fur is generally required for this group of iron proteins to be produced at physiologically relevant levels. In contrast, most proteins carrying heme molecules via noncovalent bonds, such as catalases and $b d$ oxidase (to name a few), were produced at levels comparable to those in the wildtype and $\Delta$ fur strains (10 out of 15) (Figure 2). As the Fur loss compromises the cyt $c$ biosynthesis by lowering heme levels, this observation suggests that these proteins are rather resilient to heme shortage. Intriguingly, all three of the heme-containing proteins with increased abundance in the $\Delta$ fur strain, regardless of heme-attachment types (covalent or non-covalent), function to decompose hydrogen peroxide $\left(\mathrm{H}_{2} \mathrm{O}_{2}\right)$, implying that they are concertedly regulated in responsive to oxidative stress.

The largest family of bacterial iron proteins constitute those with $\mathrm{Fe}-\mathrm{S}$ clusters as cofactors (mostly in $2 \mathrm{Fe}-2 \mathrm{~S}$ and $4 \mathrm{Fe}-4 \mathrm{~S}$ forms, $\sim 80$ in E. coli), most of which play roles in energy-related processes, such as respiration and metabolism (Py and Barras, 2010). According to the genome annotation and the result of BLASTp against the E. coli Fe-S proteome, we identified more than 90 Fe-S proteins in S. oneidensis (Supplementary Table S2). The majority of these proteins $(54.4 \%)$ were not significantly affected by the Fur loss in terms of protein abundance, whereas $26.2 \%$ and none were found to be present less and more,

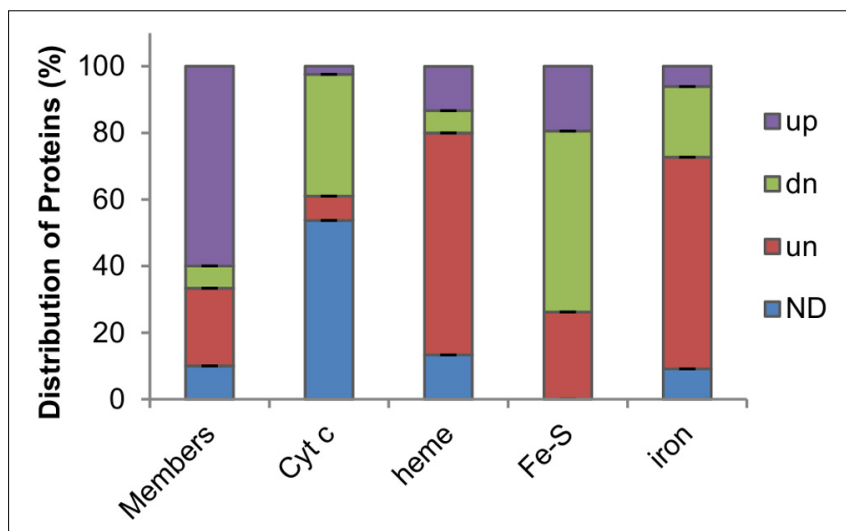

FIGURE 2 | Impacts of Fur loss on levels of Fur regulon members and iron proteins in $\mathrm{S}$. oneidensis. Members, proteins whose coding genes carry a Fur-binding motif ranked in top 30. Cyt c, cytochrome $c$ proteins. Heme, heme-containing proteins other than cyt $c$. Fe-S, proteins carrying any kind of Fe-S clusters. Iron, proteins that bind to and traffic iron or use iron as a cofactor. Up-regulated (up), down-regulated (dn), and unchanged (un) abundance (1.5-fold) in the fur mutant based on the proteomic data; ND, no data. respectively, in the $\Delta$ fur strain (Figure 2). Similar results were observed from the last group of iron proteins (33 in total), including mono- and di-nuclear iron enzymes, iron-binding (traffic and storage) proteins, and unspecified iron proteins, all of which do not need an assembly process for their iron molecules. Among them, the majority (64\%) was not significantly affected by the Fur loss, whereas those present at decreased and increased levels in the $\Delta$ fur strain were 7 and 3, respectively (Figure 2). Altogether, the proteomics data suggest that Fur inactivation derepresses of most of its regulon members, imposes critical inhibition on cyt $c$ biosynthesis, and modestly and negatively influences proteins with iron cofactors requiring complexation.

\section{Impacts of the Fur Loss on Activity of Iron Proteins Differ}

Iron proteins could be readily divided into two types: Type I iron proteins require an assembly process for their iron molecules to form complex iron cofactors, such as Fe-S clusters and heme, and Type II do not (Solomon et al., 2000; Py and Barras, 2010). Given that the cyt $c$ content is significantly reduced upon Fur inactivation (Fu et al., 2018), Type I iron proteins likely suffer from iron shortage. In contrast, as mono- and bi-nuclear iron enzymes exist in the dynamic equilibrium between demetalation and remetallation, the majority of these enzymes are functional at any moment, and thus Type II iron proteins may not be influenced by Fur inactivation (Imlay, 2014).

To test that Fur inactivation differently impacts on activity of these two types of iron enzymes in addition to affecting their quantity, for a comparative analysis we selected two heme proteins, three $\mathrm{Fe}-\mathrm{S}$ proteins, and three mononuclear iron proteins, whose activities could be specifically evaluated. Two heme proteins were catalase KatB and cyt bd oxidase (cyt bd) (Fu et al., 2013; Jiang et al., 2014), which differ from cyt $c$ in that they carry non-covalent heme and therefore are independent of cyt $c$ biosynthesis (Fu et al., 2015). Fe$\mathrm{S}$ proteins included dihydroxy-acid dehydratase (IlvD, 2Fe-2S), aconitase (AcnB, 4Fe-4S), and fumarase (FumB, 4Fe-4S); the former is involved in branched-chain amino acid biosynthesis and the latter two are essential in the TCA cycle (Py and Barras, 2010). Those employing a bound catalytic iron atom (mononuclear) that coordinates substrate included threonine dehydrogenase (Tdh), ribulose 5-phosphate 3-epimerase (Rpe), and peptide deformylase (Def1) (Imlay, 2014). All these iron proteins except for KatB, whose quantity increased 2.49 times, were not significantly affected by Fur inactivation in terms of intracellular abundance (Supplementary Table S2).

Catalase assays were performed with cell extracts in order to avoid the interference of electron-dependent peroxidases (Jiang et al., 2014). Results revealed that the $\Delta$ fur strain had a significantly enhanced capacity of decomposing $\mathrm{H}_{2} \mathrm{O}_{2}$ over the wild-type whereas a $k a t B$ null mutant was largely impotent (Figure 3A). Activity of cyt $b d$ was assayed by monitoring susceptibility to nitrite because the enzyme confers $S$. oneidensis cells nitrite tolerance (Fu et al., 2013). The $\Delta$ fur strain was more sensitive to nitrite than the wild-type, suggesting that the Fur loss impairs activity of cyt $b d$ (Figure 3B). Activities of all three Fe-S 

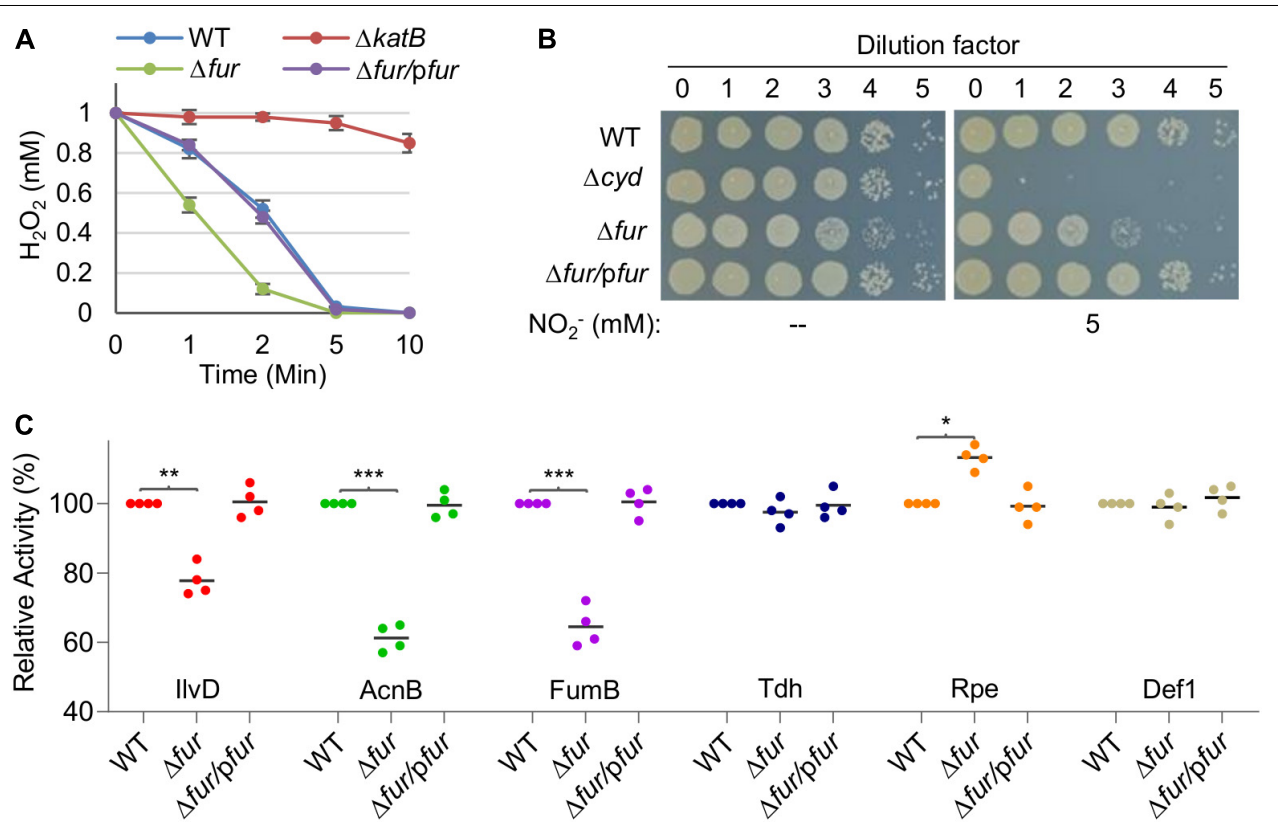

FIGURE 3 | The Fur loss affects activity of iron-proteins differently. (A) Activity of heme protein catalase determined by $\mathrm{H}_{2} \mathrm{O}_{2}(1 \mathrm{mM})$ decomposition assay. Cells of indicated strains grown to the mid-exponential phase were collected and adjusted to the same OD values. An aliquot of $200 \mu /$ was mixed with $\mathrm{H}_{2} \mathrm{O}_{2}$ and the remaining amounts were determined at indicated times. WT, the wild-type. $\Delta$ fur/pfur, the fur null mutant is complemented with a copy of the fur gene in trans. A mutant lacking catalase KatB, which dictates $\mathrm{H}_{2} \mathrm{O}_{2}$ scavenging capacity of $S$. oneidensis, was used as the negative control. (B) Activity of heme protein cyt bd oxidase determined by nitrite susceptibility with droplet assays. Cultures at the mid-exponential phase prepared to contain approximately $10^{8}$ cfu/ml were regarded as the undiluted (dilution factor, 0 ), which were subjected to 10-fold serial dilution. Five microliters of each dilution was dropped on agar plates with nitrite at indicated concentrations. Results were recorded after $24 \mathrm{~h}$ incubation. (C) Activity of Fe-S and mono-nuclear proteins determined by respective enzymatic assays. Enzymes included dihydroxy-acid dehydratase (IlvD, 2Fe-2S), aconitase (AcnB, 4Fe-4S), fumarase (FumB, 4Fe-4S), threonine dehydrogenase (Tdh, mono-), ribulose 5-phosphate 3-epimerase (Rpe, mono-), and peptide deformylase (def1, mono-). The activity of each enzyme in the wild-type was set to 100\%. Asterisks indicate statistically significant difference of the value compared to that of WT $\left({ }^{\star} P<0.05 ;{ }^{\star \star} P<0.01\right.$; $\left.{ }^{\star \star \star} P<0.001\right)$. Experiments were performed at least three times, and data were presented as means \pm SEM or as values representative of similar results.

enzymes under test were significantly lower, by up to $40 \%$, in the $\Delta$ fur strain than in the wild-type strain (Figure 3C). In contrast, mononuclear enzymes exhibited either comparable or elevated activities in the absence of Fur (Figure 3C). These data suggest that iron proteins carrying complex iron cofactors are subjected to negative regulation when Fur is inactivated.

\section{The Fur Loss Down-Regulates Heme $b$ Levels by Accelerating Heme Degradation}

The most evident phenotype resulting from the Fur loss is decolorization of cell pellets, a reflect of substantially compromised cyt $c$ biosynthesis (Fu et al., 2018; Figure 4A). Given that the Fur loss down-regulates expression of the hemA gene (Figure 1), which encodes the enzyme for the rate-limiting step in heme $b$ biosynthesis (Dailey et al., 2017; Fu et al., 2018), we examined the contribution of HemA to the lowered cellular heme $b$ levels in the $\Delta$ fur strain. In an attempt to elevate heme $b$ levels by overproducing HemA, expression of the hemA gene was driven by IPTG-inducible promoter Ptac within pHGEN-Ptac (Meng et al., 2018a). To avoid interference of heme $c$, the analysis was carried out in a strain devoid of the $c c m F$ gene, which encodes the essential heme lyase for cyt $c$ biosynthesis
(Kranz et al., 2009; Fu et al., 2015). In the wild-type cells, expression of the hem $A$ gene increased heme $b$ levels significantly with IPTG at $0.1 \mathrm{mM}$ or higher concentrations (Figure $4 \mathrm{~B}$ and Supplementary Figure S2). However, the same operation failed to confer the $\Delta$ fur strain ability to produce more heme $b$ with up to $0.5 \mathrm{mM}$ IPTG. Moreover, in the presence of extra iron, the heme $b$ levels were only modestly enhanced (Figure 4B). These data suggest that the lowered heme $b$ levels in the $\Delta$ fur strain may not be critically determined by heme $b$ biosynthesis.

The proteomic data revealed that the hemin uptake pathway was highly up-regulated upon Fur loss (Figure 4C). The pathway is composed of an outer-membrane receptor (HmuA), an energy transducing system (TonB1-ExbB1-ExbD1) located in the inner membrane, an ATP transporter system (HmuT-HmuU-HmuV), a cytoplasmic hemin binding-shuttling protein (HmuX), and a heme oxygenase (HmuZ) (Richard et al., 2019; Figure 1). Given that there is little exogenous hemin for uptake under experimental conditions, we hypothesized that HmuX and HmuZ produced at highly elevated levels may break down heme $b$ molecules that are newly synthesized endogenously, resulting in lowered heme $b$ levels.

To test this, we first verified the role of the hmuAXZ operon in heme utilization. In S. oneidensis, PutA is the TDSR specific for its own siderophores and the Feo complex (composed of FeoA 


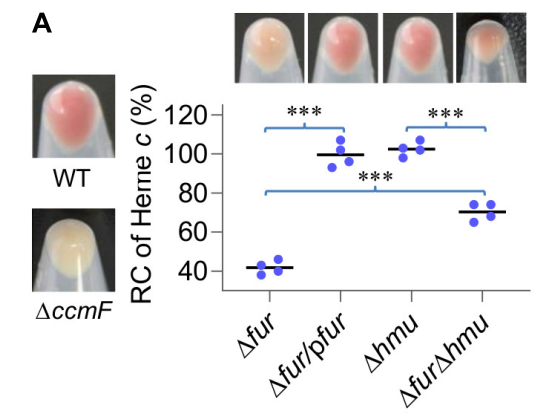

D

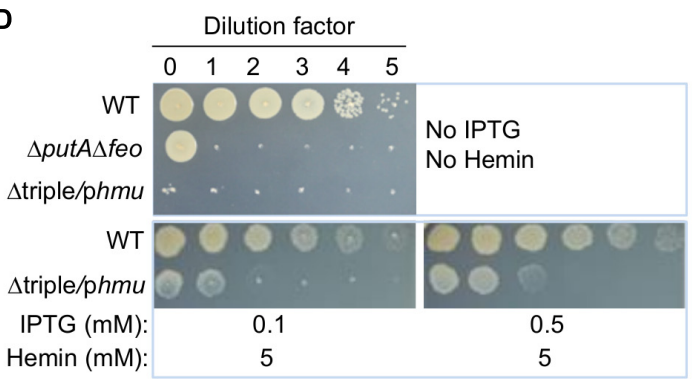

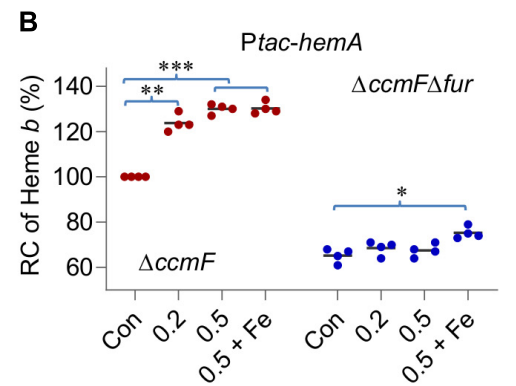

C

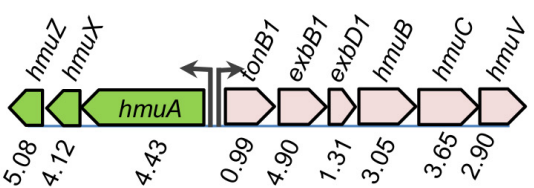

$500 \mathrm{bp}$

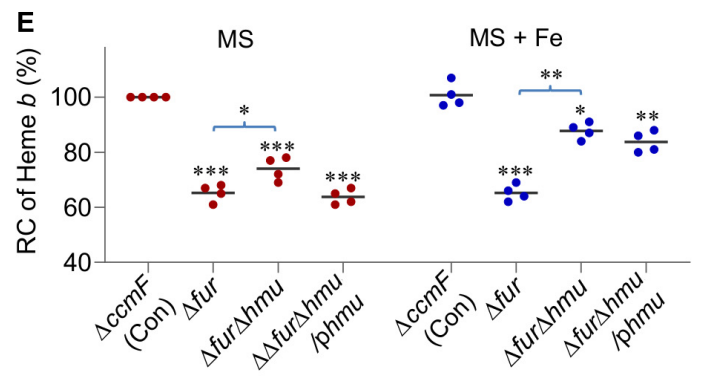

FIGURE 4 | The Fur loss down-regulates heme $b$ levels by accelerating heme degradation. (A) Heme $c$ levels in relevant strains. Cultures of indicated strains entering the stationary phase were pelleted, photographed, and lysed for quantification of heme $c$ levels. $\Delta h m u, \Delta h m u A X Z$. RC, relative concentration. The average heme $c$ levels in WT and $\Delta c c m F$ was set to $100 \%$ and $0 \%$, respectively. Asterisks indicate statistically significant differences between values linked by bracket ${ }^{\star} P<0.05$; ${ }^{\star \star} P<0.01$; $\left.{ }^{\star \star \star} P<0.001\right)$. (B) Effects of HemA overproduction on heme $b$ levels. Overproduction was driven by the IPTG-inducible Ptac promoter (Ptac-hemA) with IPTG at indicated concentrations. Cyt $c$-deficient strains $(\Delta c c m F)$ were used to avoid the interference of heme $c$, whose heme b level was set to $100 \%$. Con, carrying empty vector. $+\mathrm{Fe}$, supplemented with $0.2 \mathrm{mM} \mathrm{FeCl}_{3}$. Asterisks indicate statistically significant difference of the value compared to that of the respective Con. (C) The gene organization of heme uptake and utilization in S. oneidensis. Proteomic data were shown as the ratio of abundance in $\triangle$ fur to WT. (D) HmuRSO is essential for heme utilization revealed by droplet assays. $\Delta$ triple, $\Delta$ putA $\Delta$ feo $\Delta h m u$; phmu, phmuAXZ driven by Ptac. (E) Effects of $h m u A X Z$ deletion on heme $b$ levels as assayed as in (B). Experiments were performed at least three times, and data were presented as means $\pm S E M$ or as values representative of similar results.

and FeoB polypeptides) is a transport system essential for ferrous iron uptake (Dong et al., 2017; Liu et al., 2018; Wang et al., 2020). As a result, a strain lacking $p u t A$ and $f e o A B$ genes ( $\triangle p u t A \Delta f e o$ ) could survive and grow only when hemin is supplemented as an iron source. In the presence of a copy of the hmu (hmuAXZ) operon under the control of IPTG-inducible promoter Ptac, the chromosomal $h m u$ operon was deleted from the $\Delta p u t A \Delta f e o$ strain. The resulting strain, $\Delta$ triple/phmu, was able to grow in the presence of IPTG but could hardly do so without it on plates supplemented with hemin (Figure 4D), indicating that the $h m u$ operon is essential for utilizing heme as an iron source.

We then removed the operon from the wild-type and $\Delta$ fur strains and determined heme $b$ levels of the resulting mutants. Deletion of the $h m u$ operon in the wild-type background did not significantly affect cell pellet color (Figure 4A) or heme $b$ levels (Figure 4E), suggesting that heme degradation is not activated in the wild-type. In contrast, the impact of the HmuAXZ loss on heme $b$ levels in the $\Delta f u r$ strain was significant; cell pellets became notably more reddish (Figure 4A) and there was $\sim 15 \%$ increase in heme $b$ levels, reaching to $79 \%$ of that of the wildtype (Figure 4E). As expected, addition of iron further improved heme $b$ levels in strains lacking the fur gene (Figure 4E). These observations were attributable to HmuAXZ because the genetic complementation was successful. Overall, the data indicate that the Fur loss lowers levels of heme $b$ by down-regulating its synthesis and up-regulating its degradation simultaneously, and the latter appears to deliver a more profound impact.

\section{The Fur Loss Activates OxyR}

Based on the data presented thus far, we have drawn a general conclusion that iron proteins with complex iron cofactors are produced less and/or show impaired activity upon Fur inactivation. However, there are exceptions. Heme-containing catalases KatB, KatG-1, and KatG-2 are produced more in the $\Delta$ fur strain than the wild-type although the latter two do not have detectable physiological activity (Jiang et al., 2014). Moreover, the same occurs to cyt $c$ peroxidase CcpA, the only cyt $c$ that is upregulated upon Fur loss. Although $S$. oneidensis has a contracted OxyR regulon, which contains only five members (Jiang et al., 2014; Wan et al., 2018), katB, katG1, and ccpA belong to the OxyR regulon. Moreover, two remaining members, DpsA and AhpCF, were produced at increased levels in the fur mutant too. These data imply that the Fur loss activates OxyR-mediated oxidative stress response. To test this, susceptibility of the $\Delta$ fur strain to $\mathrm{H}_{2} \mathrm{O}_{2}$ was examined. By using disk diffusion assay, we found that the $\Delta$ fur strain was significantly more resistant to $\mathrm{H}_{2} \mathrm{O}_{2}$ than the wild-type (Figure 5A). Similarly, survival assay revealed that the Fur loss greatly enhanced viability of $S$. oneidensis during $\mathrm{H}_{2} \mathrm{O}_{2}$ killing (Figure 5B). 


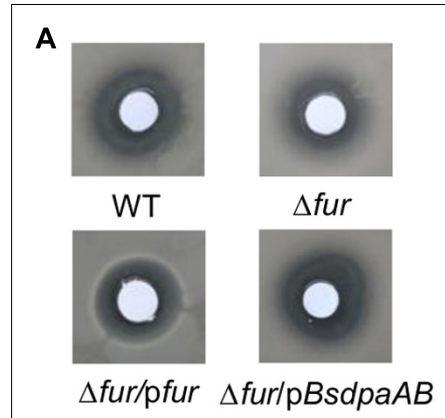

D

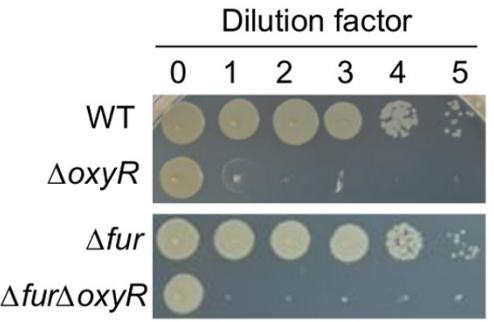

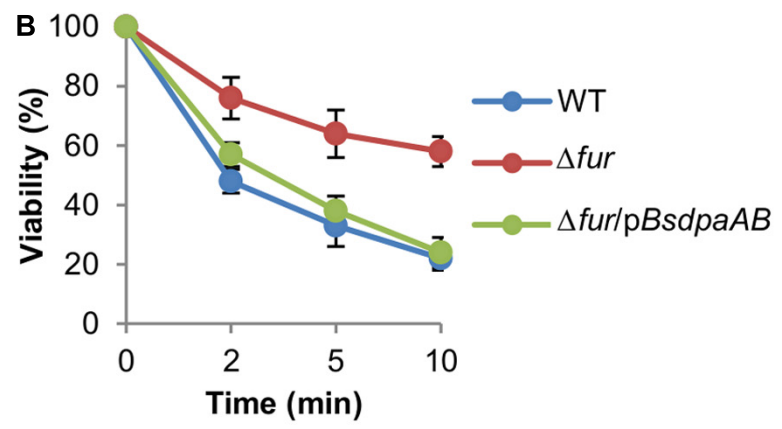

C

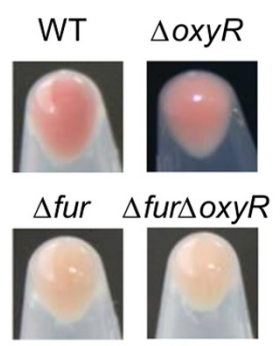

E

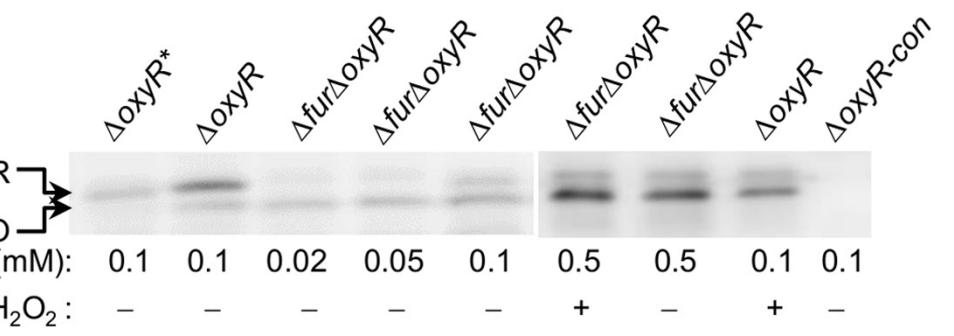

FIGURE 5| The Fur loss activates OxyR. (A,B) Effects of the fur mutation on sensitivity of $\mathrm{S}$. oneidensis to $\mathrm{H}_{2} \mathrm{O}_{2}$. $\mathrm{pBsdpaAB}, \mathrm{B}$. subtilis dpaAB gene under the control of Ptac within pHGE-Ptac. Disk diffusion assay (A): paper disks of $6 \mathrm{~mm}$ in diameter loaded with $10 \mu \mathrm{l}$ of $5 \mathrm{M} \mathrm{H}_{2} \mathrm{O}_{2}$ were placed on bacterial lawns (pre-grown for $6 \mathrm{~h}$ ). Results shown were $24 \mathrm{~h}$ after the disks were in place. Survival assay (B): $\mathrm{H}_{2} \mathrm{O}_{2}$ was added to the mid-exponential phase cultures adjusted to 0.4 of $\mathrm{OD}_{600}$ to a final concentration of $5 \mathrm{mM}$ and viable cells were counted by plating. (C,D) Physiological functions of OxyR and Fur appear non-overlapping as shown by the cell pellet color (C) and viability on LB plates (D). (E) Immunoblot analysis of OxyR. In the indicated strains, His 6 -tagged protein expression was induced with IPTG. Mid-exponential phase cells either treated with $\mathrm{H}_{2} \mathrm{O}_{2}$ of indicated concentrations for 30 min or not were collected, processed, and analyzed with antibodies against the hexahistidine tag. $\mathrm{R}$, reduced form; $\mathrm{O}$, oxidized form. Experiments were performed at least three times, and representative results are shown. ${ }^{*}$ Represents OxyR ${ }^{\mathrm{C} 203 S}$, a mutant that could not be activated. $\triangle$ oxyR-con, the $\Delta$ oxyR strain does not express a his6-tagged OxyR as the control.

According to the proteomic data, the Fur loss does not affect intracellular levels of OxyR. However, there is a putative, albeit low-confident, Fur-binding box in the promoter region of the $\operatorname{xy} R$ gene based on weight scores obtained from motif screening with RSAT (Fu et al., 2018), implying a possibility of direct regulation by Fur. We thus set out to examine the impact of Fur on transcription of the oxyR gene with qRT-PCR. Transcript abundance of the oxyR gene was not significantly different in the wild-type and $\Delta$ fur strains under same conditions, contrasting that of the $b f r$ operon used as the positive control (Supplementary Figure S3). Thus, both proteomic and transcriptomic data agree that the possibility of the $\operatorname{oxyR}$ gene being significantly regulated by Fur in terms of expression is very slim.

Then we examined activation of OxyR by the Fur loss by immunoblot analysis because OxyR proteins in reduced and oxidized forms migrate differently on SDS-PAGE (Wan et al., 2018). For this analysis, we created a $\Delta$ fur $\Delta o x y R$ strain from the $\triangle o x y R$ strain. The double deletion strain displayed phenotypes combining those from both deletions, whitened culture color, and reduced viability on LB plates (Figures 5C,D), implying that their functions are not considerably overlapping. Cells of the $\Delta o x y R$ and $\Delta$ fur $\Delta$ oxy $R$ strains expressing $\mathrm{His}_{6}$-tagged OxyR (driven by Ptac), which is fully functional (Wan et al., 2018), were grown to the mid-exponential phase $\left(\sim 0.4\right.$ of $\left.\mathrm{OD}_{600}\right)$ and collected for immunoblot analysis. As shown in Figure 5E, both reduced and oxidized OxyR proteins was found in $\mathrm{fur}^{+}(\Delta o x y R)$ cells grown under normal conditions with the reduced form dominating, while negative control OxyR ${ }^{\mathrm{C} 203 \mathrm{~S}}$, an OxyR mutant that could not form disulfide bond, was present in the reduced form only. In $\mathrm{H}_{2} \mathrm{O}_{2}$-challenged cells, the majority of OxyR proteins became oxidized. In the $f^{-} r^{-}(\Delta f u r \Delta o x y R)$ background, either treated with $\mathrm{H}_{2} \mathrm{O}_{2}$ or not, the ratio of OxyR proteins in the oxidized form to in the reduced form increased significantly (Figure 5E). These data support that the Fur loss results in activation of OxyR without significantly affecting its production.

\section{The Feo System Is Partially Responsible for Elevated Free Iron Levels in}

\section{S. oneidensis fur Mutants}

Previous analyses have shown that concentrations of the total iron and free iron in the $S$. oneidensis $\Delta$ fur strain decrease by $\sim 25 \%$ and increase by $\sim 35 \%$, respectively, compared to those in the wild-type (Fu et al., 2018). To unravel the underpinning mechanism, we looked into iron storage proteins because their E. coli functional counterparts are responsible for the same phenomenon (Andrews et al., 2003). In S. oneidensis, bacterioferritin (Bfr) is the predominant Fur-dependent iron storage protein complex whereas neither ferritin (Ftn) nor DpsA plays an important role (Fu et al., 2018; Figure 1). The removal of Bfr from the wild-type significantly reduced the levels of total iron but had little effect on free iron (Figure 6). In the absence of Fur, however, the contribution of Bfr became diminished 

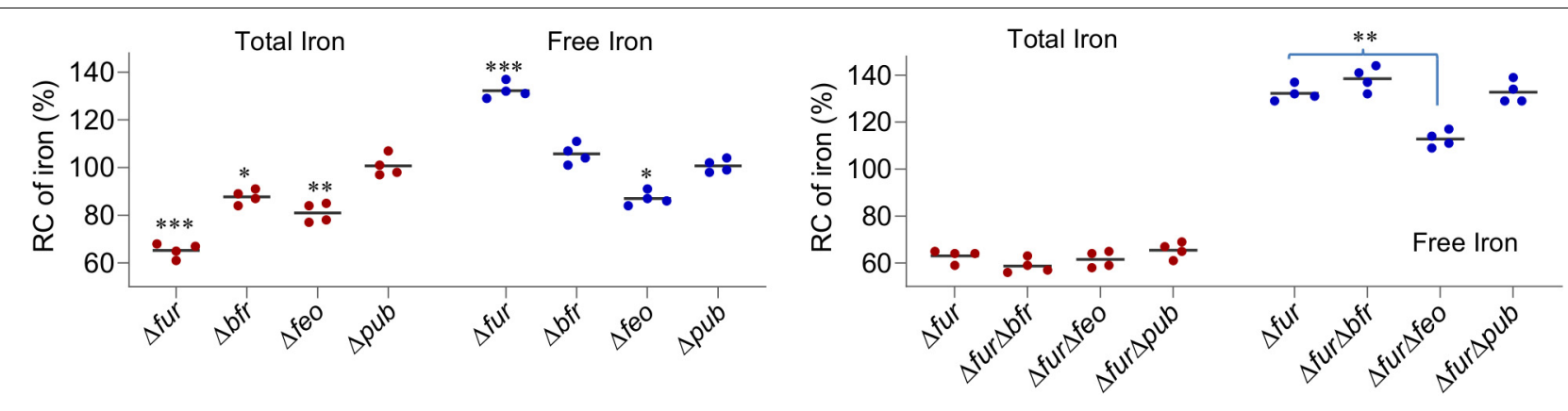

FIGURE 6 | The Feo system has a role in elevated free iron levels caused by the Fur loss. Effects of indicated deletions on cellular iron levels. Cultures of indicated strains entering the stationary phase were collected and their total iron and free iron contents were determined. The averaged levels of WT were set to $100 \%$. Asterisks indicate statistically significant differences of the value compared to that of the WT and between values linked by bracket ( ${ }^{\star} P<0.05$; ${ }^{\star \star} P<0.01$; $\left.{ }^{\star \star \star} P<0.001\right)$. Experiments were performed at least three times, and data were presented as means \pm SEM.

(Figure 6), an expected result because of its dependence on Fur for production (Fu et al., 2018). These data suggest that, upon Fur inactivation, $S$. oneidensis cells restrain iron levels not likely by limiting iron storage.

We then turned to iron uptake. In S. oneidensis, iron uptake is predominantly mediated by the ferrous iron uptake system (Feo) (Liu et al., 2018; Figure 1). According to the proteomic data, in the fur mutant the Feo system was modestly up-regulated, FeoA and FeoB, 1.27- and 1.89-fold, respectively, suggesting that this system may not be functionally compromised by the Fur loss. The contributions of the system in iron uptake in both the wildtype and $\Delta$ fur strains were then assessed. In the $f u r^{+}$background, the loss of the Feo system modestly reduced both the total and free iron levels (Figure 6). In the $\Delta$ fur $\Delta f e o$ strain, the free iron level decreased substantially but the total iron level remained comparable to that of the fur mutant (Figure 6). Reduced free iron levels in the $\Delta f e o$ and $\Delta f u r \Delta f e o$ strains were verified by enhanced resistance to streptonigrin (SNG) (Supplementary Figure S4), a redox cycling antibiotic whose antibacterial activity correlates with the levels of intracellular free iron (Wilson et al., 1998). Clearly, the Feo system is critical for elevated free iron levels caused by the Fur loss.

Next to the Feo system is the siderophore-dependent system for iron uptake in S. oneidensis (Dong et al., 2017). This system is composed of enzymes for biosynthesis of siderophores (PubABC) and proteins for their transport (PutA) and reduction (PutB, reductase), all of which are functionally essential (Liu et al., 2018; Wang et al., 2020; Figure 1). Among them, enzymes for siderophore synthesis (PubABC, 0.96, 0.36, and 0.48 -fold, respectively) were less abundant than in the wildtype, as revealed by the proteomic analysis (Supplementary Table S1). The reduction in the quantity of the PubABC enzymes concurs with the previous finding that the fur mutant secretes siderophores at significantly lowered levels (Fu et al., 2018). Consistently, PutA was not affected by the fur mutation, although most of other TDSRs were highly up-regulated (Supplementary Table S1 and Figure 1). To test if the lowered production of siderophore molecules plays a role in altered iron levels caused by Fur inactivation, we monitored iron levels in the $\Delta p u b$ and $\Delta f u r \Delta p u b$ strains. Results demonstrated that the siderophore-deficient mutation had no detectable influence on either total or free iron levels in either the wild-type or fur mutant (Figure 6). Thus, the possibility that the siderophoredependent system is a major contributing factor in S. oneidensis iron homeostasis was eliminated.

\section{The Free Iron Content Determines the Physiological Impacts of the Fur Loss}

No matter how Fur inactivation alters total iron contents in all reported cases, it elevates intracellular free iron levels. This prompts us to speculate that the elevated free iron content is a dictating factor for the observed phenotypes resulting from the Fur loss. To test this idea, effects of iron chelators, to which the cell membrane is permeable and impermeable, on the fur mutant were compared. We reasoned that the influence of desferrioxamine (DFO), a commercially available siderophore that cannot be imported into $S$. oneidensis cells and thus functions to abruptly terminate iron uptake (Liu et al., 2018), should be different from that of cell-permeant 2-2-dipyridyl, which is potentially able to lower free iron in the cytoplasm.

At 2 and $5 \mu \mathrm{M}$, DFO decreased cyt $c$ biosynthesis (whitened cell pellets, Supplementary Figure S5) and iron content of the wild-type significantly while the effect was not evident at lower concentrations (Figures 7A,B). Despite this, even $5 \mu \mathrm{M}$ DFO barely altered free iron concentrations evidenced by similar resistance to SNG (Supplementary Figure S4). In the $\Delta$ fur strain, cyt $c$ biosynthesis (the color of cell pellets, Fig. S5) was not notably affected by DFO at all test concentrations (Figure 7A). In line with this, neither total nor free iron content in the fur mutant was responsive to DFO treatment (Figure $7 \mathbf{B}$ and Supplementary Figure S4). When 2,2-dipyridyl was used, the wild-type strains responded similarly as DFO in terms of cyt $c$ biosynthesis (cell pellet color, Supplementary Figure S5) and total iron content (Figures 7A,B). However, free iron content decreased with 2,2-dipyridyl at $50 \mu \mathrm{M}$ and above (Figure 7B and Supplementary Figure S3). The $\Delta$ fur strain displayed a different scenario in responding to 2,2-dipyridyl. The cyt $c$ biosynthesis increased (the cell pellet color becoming increasingly reddish, Supplementary Figure S5) with concentrations closing 

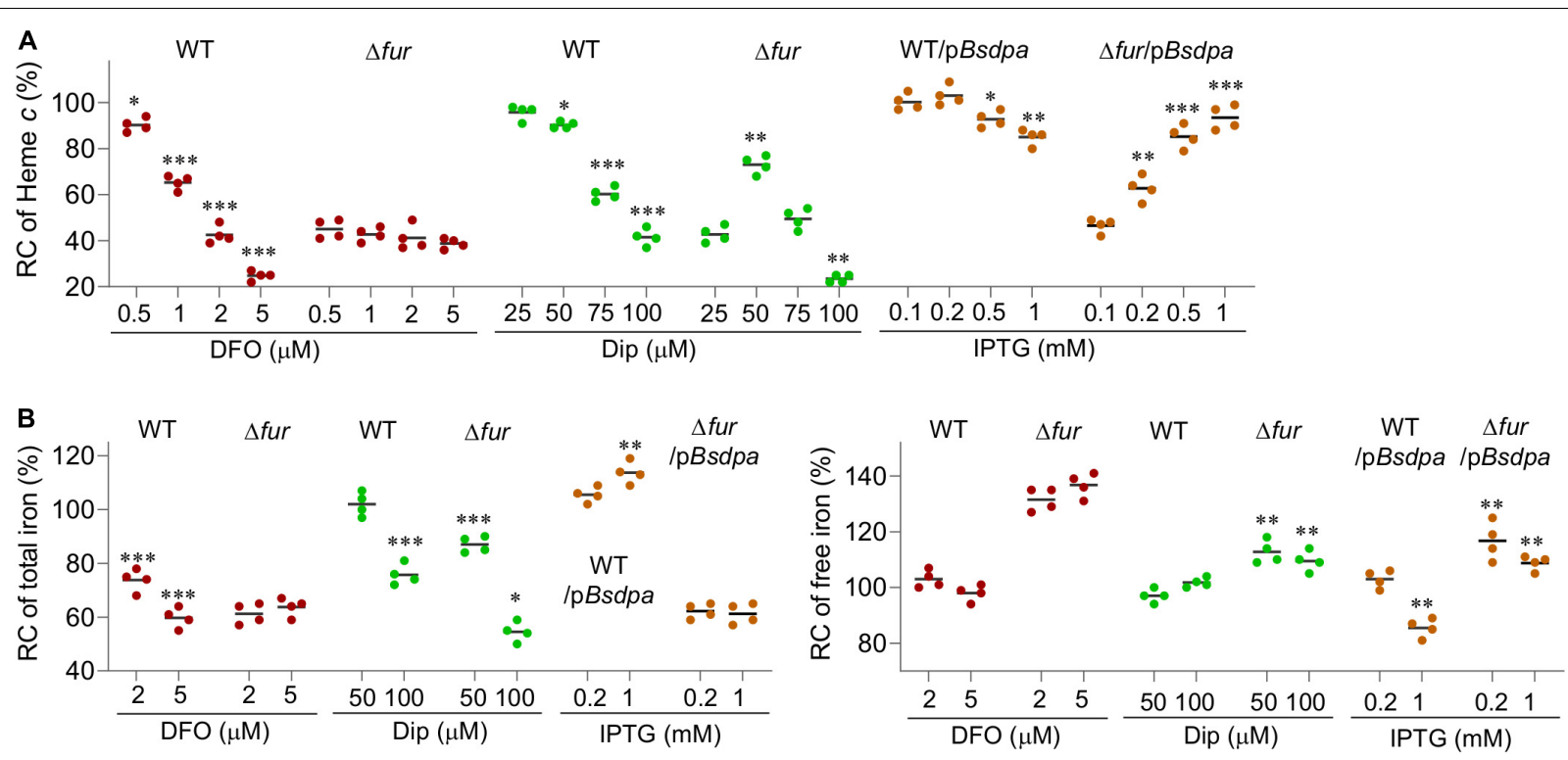

FIGURE 7| The free iron content determines the physiological impacts of the Fur loss. (A) Suppressing effects of iron chelators on the fur deletion based on cyt $C$ biosynthesis. Dip, 2,2-dipyridyl. pBsdpaAB, B. subtilis dpaAB gene under the control of Ptac within pHGE-Ptac. (B) Relative concentrations (RC) of total and free iron in WT and $\Delta$ fur strains. Cultures of indicated strains entering the stationary phase were collected and their total iron and free iron contents were determined. The averaged levels of WT were set to 100\%. Con, no chelator; DFO-2 and -5, DFO at 2 and $5 \mu$ M; Dip-50 and -100, dipyridyl at 50 and $100 \mu$ M; IPTG-0.2 and -1, $\mathrm{pBsdpaAB}$ with IPTG 0.2 and $1 \mathrm{mM}$. Asterisks indicate statistically significant differences of the value compared to that of the WT and between values linked by bracket $\left({ }^{\star} P<0.05 ;{ }^{* \star} P<0.01 ;{ }^{\star \star \star} P<0.001\right)$. Experiments were performed at least three times, and data were presented as means \pm SEM or by representative results.

to $50 \mu \mathrm{M}$, returned to the original with $75 \mu \mathrm{M}$, and became even paler with $100 \mu \mathrm{M}$. Although $50 \mu \mathrm{M}$ 2,2-dipyridyl did not significantly lower the total iron content, it reduced the free iron levels substantially (Figure 7B), conferring cells elevated resistance to SNG (Supplementary Figure S4).

Although the different effects of 2,2-dipyridyl on the wildtype and $\Delta$ fur strains strongly support that the free iron content is important for the physiological impacts of the Fur loss, additional evidence is needed because the chelator reduces extracellular iron levels simultaneously. To circumvent this, in S. oneidensis we engineered production of dipicolinate, an iron chelator that could not cross cell membranes because it is a charged molecule (Maringanti and Imlay, 1999). Bacillus subtilis dipicolinate synthetase (encoded by $B s d p a A B$ ) is able to carry out one-step conversion of dipicolinate from dihydrodipicolinate, an intermediate in the pathway of diaminopimelate and lysine biosynthesis (Hutton et al., 2007; Supplementary Figure S6). Overproduction of $B s \mathrm{DpaAB}$ in $E$. coli could substantially reduce free iron levels (Maringanti and Imlay, 1999). We placed the $B s d p a A B$ under the control of Ptac within pHGE-Ptac and introduced the resulting vector into relevant $S$. oneidensis strains. The cyt $c$ biosynthesis (cell pellet color, Supplementary Figure S5) of the wild-type was not affected by this vector with up to $1 \mathrm{mM}$ IPTG (saturated induction) (Figure 7A). In contrast, this vector significantly suppressed the cyt $c$ biosynthesis defect (the cell-pellet color, Supplementary Figure S5) of the $\Delta$ fur strain in the presence of IPTG at $0.2 \mathrm{mM}$ or higher (Figure 7A), exactly like that observed from $50 \mu \mathrm{M}$ 2,2-dipyridyl. However, cyt $c$ biosynthesis additionally increased slightly (the cell pellet color remained reddish, Supplementary Figure S5) with further increased $B s \mathrm{DpaAB}$ production, contrasting the effect of 2,2-dipyridyl at higher concentrations. Quantification of iron contents demonstrated that $B s \mathrm{DpaAB}$ produced with $0.2 \mathrm{mM}$ IPTG increased the total iron content but did not alter the free iron levels in the wild-type (Figure 7B and Supplementary Figures S4, S5). In the $\Delta$ fur strain, we found that the total iron content was barely affected but the free iron levels decreased significantly when $B s \mathrm{DpaAB}$ was produced to sufficient amounts. In addition, we found that manipulated production of $B s \mathrm{DpaAB}$ was also able to suppress the effects of Fur loss on oxidative stress response (Figures 5A,B). These data, all together, conclude that excessive free iron is largely accountable for the physiological impacts of the Fur loss.

\section{DISCUSSION}

In many bacteria, Fur proteins are now regarded as global transcriptional regulators, controlling a large number of genes participating in diverse biological processes, such as redox regulation, energy metabolism, defenses against oxidative and nitrosative stresses, nucleic acid biosynthesis, cell morphology and motility, and many more (Jittawuttipoka et al., 2010; Yu and Genco, 2012; Becerra et al., 2014; Fillat, 2014; González et al., 2014; Seo et al., 2014; Pasqua et al., 2017). Fur inactivation imposes upon bacterial cells an inability to maintain normal iron homeostasis, resulting in altered iron contents that triggers an array of physiological abnormalities. In metal-reducing bacteria, 
Fur regulation appears particularly important as iron is the essential cofactor for electron transport chain components and terminal reductases, especially cyts $c$ (Senko and Stolz, 2001; Thompson et al., 2002; Fredrickson et al., 2008).

The primary objective of the present study was to clarify how pleiotropic regulator Fur regulates activity of iron-containing proteins of $S$. oneidensis and to define the essence of the Fur regulation. In $S$. oneidensis, while early transcriptomics studies validated Fur as the predominant regulator for iron homeostasis (Wan et al., 2004; Yang et al., 2008), recent investigations expanded its impacts beyond iron-related processes, including induction of $\lambda$ So prophage and production of outer-membrane porins (Binnenkade et al., 2014; Gao et al., 2015). Here, we have examined influences of the Fur loss on an array of iron-containing proteins, an idea stemming from compromised overall cyt $c$ biosynthesis (Fu et al., 2018).

In $S$. oneidensis, heme $b$ is an essential molecule because respiration of all EAs known to date, including oxygen and nonoxygen ones, is absolutely dependent on heme proteins (Fu et al., 2015). Fur is involved in regulation of heme $b$ biosynthesis, a finding that is expected because the intracellular iron content is crucial for biosynthesis of heme $b$ (Dong et al., 2017). It has been previously proposed that Fur influences heme $b$ biosynthesis by affecting transcription of hem $A$, whose product catalyzes the rate-limiting step of heme $b$ biosynthesis (Dailey et al., 2017; Liu et al., 2018). However, here, we reveal an additional and more important mechanism accounting for the heavily reduced heme $b$ content in the fur mutant. Genes for heme (hemin) uptake and utilization proteins are conserved members of the Fur regulon in many bacteria, including S. oneidensis (Fu et al., 2018; Richard et al., 2019). Derepression of these genes by Fur inactivation under iron starvation conditions is a strategy for bacterial cells to obtain heme as an alternative iron source. Clearly, S. oneidensis adopts the same mechanism. Under experimental conditions, heme molecules in the extracellular milieu are too low to meet the demand of the heme utilization reductase and oxygenase, which are overproduced along with the heme import system in cells of the fur mutant. Instead, heme molecules generated endogenously appear to be victims of these utilization proteins (Richard et al., 2019), reducing intracellular heme levels. This mechanism also reasonably explains the finding that the fur mutant carries more severe defects in cyt $c$ biosynthesis than a strain lacking Crp, the most important global regulator for respiration (Saffarini et al., 2003; Yin et al., 2016; Fu et al., 2018). In S. oneidensis, the hemA gene is subject to positive regulation of Crp too and the Crp loss compromises hemA expression at least comparably, if not more severely, to the Fur inactivation. However, as Crp does not control heme uptake and utilization systems, heme levels in the crp mutant exceed those in the fur mutant (Yin et al., 2016; Fu et al., 2018).

Despite reduced production and enhanced decomposition, heme is still maintained at levels sufficiently high to ensure essential or crucial heme proteins to function in the fur mutant. It is common that multiple terminal oxidases are encoded in a bacterial genome, but one suffices to respire oxygen and therefore to support growth under aerobic conditions (Zhou et al., 2013). In S. oneidensis, the primary oxidase for oxygen respiration is cyt $c$ oxidase $c b b_{3}$ while cyt $b d$ oxidase functions as an auxiliary enzyme to reduce oxygen but dictates nitrite tolerance (Fu et al., 2013; Zhou et al., 2013). In the absence of Fur, the primary oxidase, cyt $c$ oxidase $c b b_{3}$, is substantially impaired; to survive and to grow, cells have to rely on cyt $b d$ oxidase for oxygen respiration (Fu et al., 2018). The proteomic data show that the quantity of cyt $b d$ is barely affected by the Fur loss. This concurs with the previous observations that there is no compensating production for cyt $b d$ when cyt $c b b_{3}$ is depleted (Yin et al., 2016; Zhang et al., 2020). Nonetheless, activity of cyt $b d$ is significantly impaired upon Fur inactivation, evidenced by increased susceptibility to nitrite (Fu et al., 2013; Meng et al., 2018b; Zhang et al., 2020). We therefore suggest that Fur inactivation results in heme $b$ shortage, which retards the assembling process for cyt $b d$ to be a functional enzyme. By the same token, the Fur loss causes reduced activity of F-S enzymes tested in this study as biosynthesis of iron-sulfur clusters is also a complex process involving a consortium of highly conserved proteins (Frazzon et al., 2002). On the contrary, Fur hardly shows noticeable impact on production and activity of proteins that use iron atom as cofactors directly, such as mononuclear proteins.

In bacteria, it is well established that the control of iron homeostasis and responses to oxidative stress are coordinated (Cornelis et al., 2011). E. coli fur mutants were found to be hypersensitive to $\mathrm{H}_{2} \mathrm{O}_{2}$ more than 2 decades ago (Touati et al., 1995), and since then, similar phenomena have been observed in most, if not all, of the bacteria in which the subject was studied (Cornelis et al., 2011). The underpinning mechanism is that Fur inactivation leads to unrestrained iron uptake and diminished iron consumption due to reduced production of iron proteins, resulting in elevated iron contents, free iron in particular, which eventually promotes hydroxyl radical generation via Fenton chemistry. However, this is not the case in S. oneidensis. The OxyR regulon of $S$. oneidensis is rather small, containing only 5 members (Jiang et al., 2014; Wan et al., 2018). Four of them are iron-containing proteins, catalases KatB and KatG1, cyt $c$ peroxidase CcpA, and iron-storage protein DpsA, all of which display increased expression in the fur mutant, in contrast to most of their kind. In addition, the only non-iron member of the OxyR regulon, AhpCF (NADH peroxidase), is also present in increased quantity. We show here that the Fur loss modulates the redox status rather than the quantity of OxyR proteins, which exist in both reduced and oxidized forms at the same time (Wan et al., 2018). By reducing the ratio of the reduced to the oxidized, the Fur depletion results in overall activation of the regulator. Thus, although the free iron level becomes elevated upon Fur inactivation in S. oneidensis, cells manage to trigger prompt responses to oxidative stress for protection. We speculate that evolution has honed Shewanella for their strategy to copy with excessive iron because they live in redox-stratified niches and contain unusually high concentrations of iron comparing to model bacteria, such as E. coli (Daly et al., 2004; Jiang et al., 2014).

A common consequence of the Fur loss is iron overload, a scenario that is in line with the repressing role of Fur for iron acquisition (Vajrala et al., 2011; Latorre et al., 2018). Although a large portion of these studies do not distinguish between free iron and iron bound to proteins, it is reasonable 
to assume that the free iron content increases, as revealed in a few (Jittawuttipoka et al., 2010; Latorre et al., 2018). An increase in the free iron content upon Fur inactivation is also observed in some other bacteria, such as E. coli and S. oneidensis, despite a decrease in the total iron content (Keyer and Imlay, 1996; Abdul-Tehrani et al., 1999). To date, exceptions to elevated free iron content resulting from the Fur loss have been exclusively observed in $\alpha$-proteobacteria, such as Bradyrhizobium japonicum, Rhizobium leguminosarum, Agrobacterium tumefaciens, and so forth (O'Brian, 2015). In these bacteria, Fur-like proteins have either been initially found to physiologically function in response to other metals or senses iron indirectly (Qi and O’Brian, 2002; O'Brian, 2015). Thus, it seems that regulation of response to iron availability in $\alpha$-proteobacteria evolves differently from other bacteria employing Fur as the master iron-responsive regulator, in which Fur inactivation generally leads to increased free iron content.

In this study, our data suggest that the increased free iron content upon Fur loss is the key to trigger the physiological abnormalities. The first piece of evidence comes from the observation that membrane-permeable chelator dipyridyl but not impermeable DFO, when present at proper levels, could restore cyt $c$ biosynthesis in the fur mutant. The successful suppression of the cyt $c$ biosynthesis defect by dipicolinate, a chelator that functions only intracellularly, provides more rigid support. Although the connections between the elevated free iron content and Fur inactivation remain to be uncovered, we speculate that the presence of excessive free iron would signal and prevent more iron uptake despite an up-regulated iron uptake system in the fur mutant. Despite this, given that the cellular storage capacity is heavily discounted, the fur mutant would maintain a high level of free iron content. It should be noted that the cellular storage proteins, even forcibly produced to considerable quantity, are not effective as chelators tested here (Fu et al., 2018). We do not yet understand the mechanism behind

\section{REFERENCES}

Abdul-Tehrani, H., Hudson, A. J., Chang, Y.-S., Timms, A. R., Hawkins, C., Williams, J. M., et al. (1999). Ferritin mutants of Escherichia coli are iron deficient and growth impaired, and fur mutants are iron deficient. J. Bacteriol. 181, 1415-1428. doi: 10.1128/jb.181.5.1415-1428.1999

Andrews, S. C., Robinson, A. K., and Rodríguez-Quiñones, F. (2003). Bacterial iron homeostasis. FEMS Microbiol. Rev. 27, 215-237. doi: 10.1016/s0168-6445(03) 00055-x

Becerra, G., Merchán, F., Blasco, R., and Igeño, M. I. (2014). Characterization of a ferric uptake regulator (Fur)-mutant of the cyanotrophic bacterium Pseudomonas pseudoalcaligenes CECT5344. J. Biotechnol. 190, 2-10. doi: 10. 1016/j.jbiotec.2014.03.030

Berry, E. A., and Trumpower, B. L. (1987). Simultaneous determination of hemes a, b, and c from pyridine hemochrome spectra. Anal. Biochem. 161, 1-15. doi: 10.1016/0003-2697(87)90643-9

Binnenkade, L., Teichmann, L., and Thormann, K. M. (2014). Iron triggers $\lambda$ So prophage induction and release of extracellular DNA in Shewanella oneidensis MR-1 biofilms. Appl. Environ. Microbiol. 80, 5304-5316. doi: 10.1128/aem. 01480-14

Boylan, S. A., and Dekker, E. E. (1981). L-threonine dehydrogenase. Purification and properties of the homogeneous enzyme from Escherichia coli K-12. J. BIol. Chem. 256, 1809-1815. this. One may imagine that the free iron pool is restricted by both iron storage proteins and small molecule chelators in the wild-type cells and production of both is compromised by Fur activation. We are working to test this notion.

\section{DATA AVAILABILITY STATEMENT}

The mass spectrometry proteomics data have been deposited to the ProteomeXchange Consortium (http://proteomecentral. proteomexchange.org) via the iProX partner repository with the dataset identifier PXD021732.

\section{AUTHOR CONTRIBUTIONS}

LL, XF, WW, YC, and ZC conducted and performed the experiments. $\mathrm{LL}$ and $\mathrm{XF}$ contributed to data discussion and analysis. HG designed and supervised the study, and wrote the manuscript with LL. All authors contributed to the article and approved the submitted version.

\section{FUNDING}

This research was supported by the National Natural Science Foundation of China (31930003 and 41976087) and by Ten Thousand Talents Program of China.

\section{SUPPLEMENTARY MATERIAL}

The Supplementary Material for this article can be found online at: https://www.frontiersin.org/articles/10.3389/fmicb. 2020.593246/full\#supplementary-material

Chen, H., Luo, Q., Yin, J., Gao, T., and Gao, H. (2015). Evidence for the requirement of CydX in function but not assembly of the cytochrome bd oxidase in Shewanella oneidensis. Biochim. Biophys. Acta 1850, 318-328. doi: 10.1016/j. bbagen.2014.10.005

Cornelis, P., Wei, Q., Andrews, S. C., and Vinckx, T. (2011). Iron homeostasis and management of oxidative stress response in bacteria. Metallomics 3, 540-549. doi: $10.1039 / \mathrm{clmt} 00022 \mathrm{e}$

Dailey, H. A., Dailey, T. A., Gerdes, S., Jahn, D., Jahn, M., O’Brian, M. R., et al. (2017). Prokaryotic heme biosynthesis: multiple pathways to a common essential product. Microbiol. Mol. Biol. Rev. 81, e48-e16.

Daly, M. J., Gaidamakova, E. K., Matrosova, V. Y., Vasilenko, A., Zhai, M., Venkateswaran, A., et al. (2004). Accumulation of $\mathrm{Mn}(\mathrm{II})$ in Deinococcus radiodurans facilitates gamma-radiation resistance. Science 306, 1025-1028. doi: $10.1126 /$ science. 1103185

Dong, Y., Wang, J., Fu, H., Zhou, G., Shi, M., and Gao, H. (2012). A Crp-dependent two-component system regulates nitrate and nitrite respiration in Shewanella oneidensis. PLoS One 7:e51643. doi: 10.1371/journal.pone.0051643

Dong, Z., Guo, S., Fu, H., and Gao, H. (2017). Investigation of a spontaneous mutant reveals novel features of iron uptake in Shewanella oneidensis. Sci. Rep. $7: 11788$.

Fillat, M. F. (2014). The FUR (ferric uptake regulator) superfamily: diversity and versatility of key transcriptional regulators. Arch. Biochem. Biophys. 546, 41-52. doi: 10.1016/j.abb.2014.01.029 
Flint, D. H., Emptage, M. H., Finnegan, M. G., Fu, W., and Johnson, M. K. (1993). The role and properties of the iron-sulfur cluster in Escherichia coli dihydroxy-acid dehydratase. J. Biol. Chem. 268, 14732-14742.

Frawley, E. R., and Fang, F. C. (2014). The ins and outs of bacterial iron metabolism. Mol. Microbiol. 93, 609-616.

Frazzon, J., Fick, J. R., and Dean, D. R. (2002). Biosynthesis of iron-sulphur clusters is a complex and highly conserved process. Biochem. Soc. Trans. 30, 680-685. doi: $10.1042 /$ bst0300680

Fredrickson, J. K., Romine, M. F., Beliaev, A. S., Auchtung, J. M., Driscoll, M. E., Gardner, T. S., et al. (2008). Towards environmental systems biology of Shewanella. Nat. Rev. Micro. 6, 592-603.

Fu, H., Chen, H., Wang, J., Zhou, G., Zhang, H., Zhang, L., et al. (2013). Crpdependent cytochrome bd oxidase confers nitrite resistance to Shewanella oneidensis. Environ. Microbiol. 15, 2198-2212. doi: 10.1111/1462-2920.12091

Fu, H., Jin, M., Wan, F., and Gao, H. (2015). Shewanella oneidensis cytochrome c maturation component $\mathrm{CcmI}$ is essential for heme attachment at the noncanonical motif of nitrite reductase NrfA. Mol. Microbiol. 95, 410-425. doi: 10.1111/mmi. 12865

Fu, H., Liu, L., Dong, Z., Guo, S., and Gao, H. (2018). Dissociation between iron and heme biosynthesis is largely accountable for respiration defects of Shewanella oneidensis fur mutants. Appl. Environ. Microbiol. 84, e39-e18.

Gao, H., Barua, S., Liang, Y., Wu, L., Dong, Y., Reed, S., et al. (2010). Impacts of Shewanella oneidensis c-type cytochromes on aerobic and anaerobic respiration. Microb. Biotechnol. 3, 455-466. doi: 10.1111/j.1751-7915.2010.00181.x

Gao, T., Ju, L., Yin, J., and Gao, H. (2015). Positive regulation of the Shewanella oneidensis OmpS38, a major porin facilitating anaerobic respiration, by Crp and Fur. Sci. Rep. 5:14263.

González, A., Angarica, V. E., Sancho, J., and Fillat, M. F. (2014). The FurA regulon in Anabaena sp. PCC 7120: in silico prediction and experimental validation of novel target genes. Nucleic Acids Res. 42, 4833-4846. doi: 10.1093/nar/gku123

Hutton, C. A., Perugini, M. A., and Gerrard, J. A. (2007). Inhibition of lysine biosynthesis: an evolving antibiotic strategy. Mol. BioSyst. 3, 458-465. doi: $10.1039 / \mathrm{b} 705624 \mathrm{a}$

Imlay, J. A. (2013). The molecular mechanisms and physiological consequences of oxidative stress: lessons from a model bacterium. Nat. Rev. Micro. 11, 443-454. doi: $10.1038 /$ nrmicro3032

Imlay, J. A. (2014). The mismetallation of enzymes during oxidative stress. J. Biol. Chem. 289, 28121-28128. doi: 10.1074/jbc.r114.588814

Jiang, Y., Dong, Y., Luo, Q., Li, N., Wu, G., and Gao, H. (2014). Protection from oxidative stress relies mainly on derepression of OxyR-dependent KatB and Dps in Shewanella oneidensis. J. Bacteriol. 196, 445-458. doi: 10.1128/jb.01077-13

Jin, M., Jiang, Y., Sun, L., Yin, J., Fu, H., Wu, G., et al. (2013). Unique organizational and functional features of the cytochrome c maturation system in Shewanella oneidensis. PLoS One 8:e75610. doi: 10.1371/journal.pone.0075610

Jittawuttipoka, T., Sallabhan, R., Vattanaviboon, P., Fuangthong, M., and Mongkolsuk, S. (2010). Mutations of ferric uptake regulator (fur) impair iron homeostasis, growth, oxidative stress survival, and virulence of Xanthomonas campestris pv. campestris. Arch. Microbiol. 192, 331-339. doi: 10.1007/s00203010-0558-8

Keyer, K., and Imlay, J. A. (1996). Superoxide accelerates DNA damage by elevating free-iron levels. Proc. Natl. Acad. Sci. U.S.A. 93, 13635-13640. doi: 10.1073/ pnas.93.24.13635

Kiely, M. E., Stuart, A. L., and Wood, T. (1973). Partial purification and kinetic properties of ribose-5-phosphate ketol-isomerase and ribulose-5-phosphate 3epimerase from various sources. Biochim. Biophys. Acta 293, 534-541. doi: 10.1016/0005-2744(73)90360-4

Kitphati, W., Ngok-ngam, P., Suwanmaneerat, S., Sukchawalit, R., and Mongkolsuk, S. (2007). Agrobacterium tumefaciens fur has important physiological roles in iron and manganese homeostasis, the oxidative stress response, and full virulence. Appl. Environ. Microbiol. 73, 4760-4768. doi: 10.1128/aem.00531-07

Kranz, R. G., Richard-Fogal, C., Taylor, J.-S., and Frawley, E. R. (2009). Cytochrome $c$ biogenesis: mechanisms for covalent modifications and trafficking of heme and for heme-iron redox control. Microbiol. Mol. Biol. Rev. 73, 510-528. doi: 10.1128/mmbr.00001-09

Latorre, M., Quenti, D., Travisany, D., Singh, K. V., Murray, B. E., Maass, A., et al. (2018). The role of Fur in the transcriptional and iron homeostatic response of Enterococcus faecalis. Front. Microbiol. 9:1580. doi: 10.3389/fmicb.2018.01580
Lazennec, C., and Meinnel, T. (1997). Formate dehydrogenase-coupled spectrophotometric assay of peptide deformylase. Anal. Biochem. 244, 180-182. doi: 10.1006/abio.1996.9910

Lemaire, O. N., Méjean, V., and Iobbi-Nivol, C. (2020). The Shewanella genus: ubiquitous organisms sustaining and preserving aquatic ecosystems. FEMS Microbiol. Rev. 44, 155-170. doi: 10.1093/femsre/fuz031

Liu, J., Chakraborty, S., Hosseinzadeh, P., Yu, Y., Tian, S., Petrik, I., et al. (2014). Metalloproteins containing cytochrome, iron-sulfur, or copper redox centers. Chem Rev 114, 4366-4469. doi: 10.1021/cr400479b

Liu, L., Li, S., Wang, S., Dong, Z., and Gao, H. (2018). Complex iron uptake by the putrebactin-mediated and Feo systems in Shewanella oneidensis. Appl. Environ. Microbiol. 84, e1752-e1718.

Lovley, D. R., Ueki, T., Zhang, T., Malvankar, N. S., Shrestha, P. M., Flanagan, K. A., et al. (2011). "Geobacter: the microbe electric's physiology, ecology, and practical applications," in Adv Microbial Physiol, ed. R. K. Poole (Cambridge, MA: Academic Press), 1-100.

Maringanti, S., and Imlay, J. A. (1999). An intracellular iron chelator pleiotropically suppresses enzymatic and growth defects of superoxide dismutase-deficient Escherichia coli. J. Bacteriol. 181, 3792-3802. doi: 10.1128/jb.181.12.3792-3802. 1999

Massey, V. (1955). “[122] fumarase: fumarate + water $\leftrightarrows 1$-malate," in Methods in Enzymology (Cambridge, MA: Academic Press), 729-735.

Medina-Rivera, A., Defrance, M., Sand, O., Herrmann, C., Castro-Mondragon, J. A., Delerce, J., et al. (2015). RSAT 2015: regulatory sequence analysis tools. Nucleic Acids Res. 43, W50-W56.

Meng, Q., Liang, H., and Gao, H. (2018a). Roles of multiple KASIII homologues of Shewanella oneidensis in initiation of fatty acid synthesis and in cerulenin resistance. Biochim. Biophys. Acta 1863, 1153-1163. doi: 10.1016/j.bbalip.2018. 06.020

Meng, Q., Yin, J., Jin, M., and Gao, H. (2018b). Distinct nitrite and nitric oxide physiologies in Escherichia coli and Shewanella oneidensis. Appl. Environ. Microbiol. 84, e559-e518.

Methé, B. A., Nelson, K. E., Eisen, J. A., Paulsen, I. T., Nelson, W., Heidelberg, J. F., et al. (2003). Genome of Geobacter sulfurreducens: metal reduction in subsurface environments. Science 302, 1967-1969. doi: 10.1126/science. 1088727

Meyer, T. E., Tsapin, A. I., Vandenberghe, I., De Smet, L., Frishman, D., Nealson, K. H., et al. (2004). Identification of 42 possible cytochrome c genes in the Shewanella oneidensis genome and characterization of six soluble cytochromes. OMICS 8, 57-77. doi: 10.1089/15362310477354 7499

Nissen, S., Liu, X., Chourey, K., Hettich, Robert, L., Wagner, D., et al. (2012). Comparative c-type cytochrome expression analysis in Shewanella oneidensis strain MR-1 and Anaeromyxobacter dehalogenans strain 2CP-C grown with soluble and insoluble oxidized metal electron acceptors. Biochem. Soc. Trans. 40, 1204-1210. doi: 10.1042/bst20120182

O'Brian, M. R. (2015). Perception and homeostatic control of iron in the Rhizobia and related bacteria. Annu. Rev. Microbiol. 69, 229-245. doi: 10.1146/annurevmicro-091014-104432

O’Neil, R. A., Holmes, D. E., Coppi, M. V., Adams, L. A., Larrahondo, M. J., Ward, J. E., et al. (2008). Gene transcript analysis of assimilatory iron limitation in Geobacteraceae during groundwater bioremediation. Environ. Microbiol. 10, 1218-1230. doi: 10.1111/j.1462-2920.2007.01537.x

Pasqua, M., Visaggio, D., Lo Sciuto, A., Genah, S., Banin, E., Visca, P., et al. (2017). Ferric uptake regulator Fur is conditionally essential in Pseudomonas aeruginosa. J. Bacteriol. 199:e472-17.

Py, B., and Barras, F. (2010). Building Fe-S proteins: bacterial strategies. Nat. Rev. Micro. 8, 436-446. doi: 10.1038/nrmicro2356

Qi, L., Li, J., Zhang, W., Liu, J., Rong, C., Li, Y., et al. (2012). Fur in Magnetospirillum gryphiswaldense influences magnetosomes formation and directly regulates the genes involved in iron and oxygen metabolism. PLoS One 7:e29572. doi: 10.1371/journal.pone.0029572

Qi, Z., and O'Brian, M. R. (2002). Interaction between the bacterial iron response regulator and ferrochelatase mediates genetic control of heme biosynthesis. Mol. Cell. 9, 155-162. doi: 10.1016/s1097-2765(01)00431-2

Rabaey, K., and Rozendal, R. A. (2010). Microbial electrosynthesis - revisiting the electrical route for microbial production. Nat. Rev. Micro. 8, 706-716. doi: $10.1038 /$ nrmicro2422 
Richard, K. L., Kelley, B. R., and Johnson, J. G. (2019). Heme uptake and utilization by gram-negative bacterial pathogens. Front. Cell Infect. Microbiol. 9:81. doi: 10.3389/fcimb.2019.00081

Riemer, J., Hoepken, H. H., Czerwinska, H., Robinson, S. R., and Dringen, R. (2004). Colorimetric ferrozine-based assay for the quantitation of iron in cultured cells. Anal. Biochem. 331, 370-375. doi: 10.1016/j.ab.2004.03.049

Rokob, T. A., Chalupský, J., Bím, D., Andrikopoulos, P. C., Srnec, M., and Rulíšek, L. (2016). Mono- and binuclear non-heme iron chemistry from a theoretical perspective. J. Biol. Inorg. Chem. 21, 619-644. doi: 10.1007/s00775-016-1 357-8

Saffarini, D., Schultz, R., and Beliaev, A. (2003). Involvement of cyclic AMP (cAMP) and cAMP receptor protein in anaerobic respiration of Shewanella oneidensis. J. Bacteriol. 185, 3668-3671. doi: 10.1128/jb.185.12.3668-3671.2003

Senko, J. M., and Stolz, J. F. (2001). Evidence for iron-dependent nitrate respiration in the dissimilatory iron-reducing bacterium Geobacter metallireducens. Appl. Environ. Microbiol. 67, 3750-3752. doi: 10.1128/aem.67.8.3750-3752.2001

Seo, S. W., Kim, D., Latif, H., O’Brien, E. J., Szubin, R., and Palsson, B. O. (2014). Deciphering Fur transcriptional regulatory network highlights its complex role beyond iron metabolism in Escherichia coli. Nat. Commun. 5:4910.

Sheikh, M. A., and Taylor, G. L. (2009). Crystal structure of the Vibrio cholerae ferric uptake regulator (Fur) reveals insights into metal co-ordination. Mol. Microbiol. 72, 1208-1220. doi: 10.1111/j.1365-2958.2009.06718.x

Shi, M., Wan, F., Mao, Y., and Gao, H. (2015). Unraveling the mechanism for the viability deficiency of Shewanella oneidensis oxyR null mutant. J. Bacteriol. 197, 2179-2189. doi: 10.1128/jb.00154-15

Solomon, E. I., Brunold, T. C., Davis, M. I., Kemsley, J. N., Lee, S.-K., Lehnert, N., et al. (2000). Geometric and electronic structure/function correlations in non-heme iron enzymes. Chem. Rev. 100, 235-350. doi: 10.1021/cr9900275

Thompson, D. K., Beliaev, A. S., Giometti, C. S., Tollaksen, S. L., Khare, T., Lies, D. P. et al. (2002). Transcriptional and proteomic analysis of a ferric uptake regulator (Fur) mutant of Shewanella oneidensis: possible involvement of fur in energy metabolism, transcriptional regulation, and oxidative stress. Appl. Environ. Microbiol. 68, 881-892. doi: 10.1128/AEM.68.2.881-892.2002

Touati, D., Jacques, M., Tardat, B., Bouchard, L., and Despied, S. (1995). Lethal oxidative damage and mutagenesis are generated by iron in $\Delta$ fur mutants of Escherichia coli: protective role of superoxide dismutase. J. Bacteriol. 177, 2305-2314. doi: 10.1128/jb.177.9.2305-2314.1995

Vajrala, N., Sayavedra-Soto, L. A., Bottomley, P. J., and Arp, D. J. (2011). Role of a Fur homolog in iron metabolism in Nitrosomonas europaea. BMC Microbiol. 11:37-37. doi: 10.1186/1471-2180-11-37

Varghese, S., Tang, Y., and Imlay, J. A. (2003). Contrasting sensitivities of Escherichia coli aconitases A and B to oxidation and iron depletion. J. Bacteriol. 185, 221-230. doi: 10.1128/jb.185.1.221-230.2003

Wan, F., Kong, L., and Gao, H. (2018). Defining the binding determinants of Shewanella oneidensis OxyR: implications for the link between the contracted OxyR regulon and adaptation. J. Biol. Chem. 293, 4085-4096. doi: 10.1074/jbc. ra117.001530
Wan, X.-F., VerBerkmoes, N. C., McCue, L. A., Stanek, D., Connelly, H., Hauser, L. J., et al. (2004). Transcriptomic and proteomic characterization of the Fur modulon in the metal-reducing bacterium Shewanella oneidensis. J. Bacteriol. 186, 8385-8400. doi: 10.1128/jb.186.24.8385-8400.2004

Wang, S., Liang, H., Liu, L., Jiang, X., Wu, S., and Gao, H. (2020). Promiscuous enzymes cause biosynthesis of diverse siderophores in Shewanella oneidensis. Appl. Environ. Microbiol. 86, e30-e20.

Wilson, T. J. G., Bertrand, N., Tang, J. L., Feng, J. X., Pan, M. Q., Barber, C. E., et al. (1998). The rpfA gene of Xanthomonas campestris pathovar campestris, which is involved in the regulation of pathogenicity factor production, encodes an aconitase. Mol. Microbiol. 28, 961-970. doi: 10.1046/j.1365-2958.1998.00852.x

Wolff, S. P. (1994). Ferrous ion oxidation in the presence of ferric iron indicator xylenol orange for measurement of hydroperoxides. Methods Enzymol. 223, 182-189. doi: 10.1016/s0076-6879(94)33021-2

Yang, X.-W., He, Y., Xu, J., Xiao, X., and Wang, F.-P. (2013). The regulatory role of ferric uptake regulator (Fur) during anaerobic respiration of Shewanella piezotolerans WP3. PLoS One 8:e75588. doi: 10.1371/journal.pone.0075588

Yang, Y., Harris, D. P., Luo, F., Wu, L., Parsons, A. B., Palumbo, A. V., et al. (2008). Characterization of the Shewanella oneidensis Fur gene: roles in iron and acid tolerance response. BMC Genomics 9:S11. doi: 10.1186/1471-2164-9-S1-S11

Yin, J., Meng, Q., Fu, H., and Gao, H. (2016). Reduced expression of cytochrome oxidases largely explains cAMP inhibition of aerobic growth in Shewanella oneidensis. Sci. Rep. 6:24449.

Yu, C., and Genco, C. A. (2012). Fur-mediated global regulatory circuits in pathogenic Neisseria species. J. Bacteriol. 194, 6372-6381. doi: 10.1128/jb. 00262-12

Yuan, J., Wei, B., Lipton, M., and Gao, H. (2012). Impact of ArcA loss in Shewanella oneidensis revealed by comparative proteomics under aerobic and anaerobic conditions. Proteomics 12, 1957-1969. doi: 10.1002/pmic.201100651

Zhang, Y., Guo, K., Meng, Q., and Gao, H. (2020). Nitrite modulates aminoglycoside tolerance by inhibiting cytochrome heme-copper oxidase in bacteria. Commun Biol. 3:269.

Zhou, G., Yin, J., Chen, H., Hua, Y., Sun, L., and Gao, H. (2013). Combined effect of loss of the caa3 oxidase and Crp regulation drives Shewanella to thrive in redox-stratified environments. ISME J. 7, 1752-1763. doi: 10.1038/ismej.20 13.62

Conflict of Interest: The authors declare that the research was conducted in the absence of any commercial or financial relationships that could be construed as a potential conflict of interest.

Copyright (c) 2020 Liu, Feng, Wang, Chen, Chen and Gao. This is an open-access article distributed under the terms of the Creative Commons Attribution License (CC BY). The use, distribution or reproduction in other forums is permitted, provided the original author(s) and the copyright owner(s) are credited and that the original publication in this journal is cited, in accordance with accepted academic practice. No use, distribution or reproduction is permitted which does not comply with these terms. 